\title{
Response of Ytterbium Disilicate-Silicon Environmental Barrier Coatings to Thermal Cycling in Water Vapor
}

\author{
Bradley T. Richards ${ }^{1}$, Kelly A. Young ${ }^{1}$, Foucault de Francqueville ${ }^{2}$, Stephen Sehr $^{2}$, Matthew R. \\ Begley $^{2}$, and Haydn N.G. Wadley* ${ }^{1}$ \\ ${ }^{1}$ Department of Materials Science and Engineering, University of Virginia \\ Charlottesville, Virginia 22903 \\ ${ }^{2}$ Departments of Mechanical Engineering and Materials, University of California, Santa Barbara \\ Santa Barbara, CA 93106
}

\begin{abstract}
A preliminary study of a promising bi-layer environmental barrier coating (EBC) designed to reduce the susceptibility of $\mathrm{SiC}$ composites to hot water vapor erosion is reported. The EBC system consisted of a silicon bond coat and a pore-free ytterbium disilicate (YbDS; $\mathrm{Yb}_{2} \mathrm{Si}_{2} \mathrm{O}_{7}$ ) topcoat. Both layers were deposited on $\alpha-\mathrm{SiC}$ substrates using a recently optimized air plasma spray method. The two layers of the coating system had coefficients of thermal expansion (CTE) that were well matched to that of the substrate, while the YbDS has been reported to have a moderate resistance to silicon hydroxide vapor forming reactions in water vapor rich environments. Thermal cycling experiments were conducted between $110{ }^{\circ} \mathrm{C}$ and $1316^{\circ} \mathrm{C}$ in a flowing $90 \% \mathrm{H}_{2} \mathrm{O} / 10 \% \mathrm{O}_{2}$ atmospheric pressure environment, and resulted in the formation of a thermally grown (silica) oxide (TGO) at the silicon-ytterbium disilicate interface. The TGO layer exhibited linear oxidation kinetics consistent with oxidizer diffusion through the ytterbium silicate layer controlling its thickening rate. The effective diffusion coefficient of the oxidizing species in the YbDS layer was estimated to be $2 \times 10^{-12} \mathrm{~m}^{2} \mathrm{~s}^{-1}$ at $1316^{\circ} \mathrm{C}$. Slow steam volatilization of the YbDS topcoat resulted in the formation of a thin, partially protective, high CTE ytterbium monosilicate layer on the outside of the YbDS coating. Progressive edge delamination of the coating system was observed with steam exposure time, consistent with water vapor volatilization of the TGO edges that were directly exposed to the environment. This was aided by outward bending of the delaminated region to relax TGO and YbMS surface layer stresses developed during the cooling phase of each thermal cycle.
\end{abstract}

Keywords: Environmental barrier coatings, thermal spray deposition, ytterbium silicates, silicon steam volatility

*Corresponding author: haydn@ virginia.edu

(C) 2016. This manuscript version is made available under the Elsevier user license http://www.elsevier.com/open-access/userlicense/1.0/ 


\section{Introduction}

Environmental barrier coatings (EBCs) will be needed to protect SiC-based ceramic components in future gas turbine engines. ${ }^{1}$ Their primary purpose is to eliminate the rapid volatilization of $\mathrm{SiC}$ in water vapor rich environments, ${ }^{1-6}$ while also inhibiting oxidation of SiCbased ceramic matrix composites $(\mathrm{CMCs}){ }^{7-12}$ The design of these EBCs is therefore driven by a different combination of objectives to those of the thermal barrier coating (TBC) systems that are widely used to extend the life of superalloy airfoils. ${ }^{13}$ The objective of TBC designs is to reduce a metal component's surface temperature while delaying delamination failure from oxidation, ${ }^{14,15}$ reactions with molten silicate deposits ${ }^{16,17}$ and various forms of hot corrosion. ${ }^{18-23}$ However, unlike TBC systems where coating spallation results in damage, but usually not loss of the airfoil, the premature failure of an EBC could have consequences that are much more serious, since the life of an unprotected $\mathrm{SiC}$ component in a combustion environment is likely to be short. $^{2,3,24-26}$ Since no durable EBC system for use in thermo-cyclic, water vapor rich environments has been reported to date, the development of such a coating system is of considerable importance for the implementation of SiC-based CMCs in advanced gas turbine engines.

For non-rotating applications involving several thousand hours of environmental exposure at temperatures up to $1316^{\circ} \mathrm{C}\left(2400{ }^{\circ} \mathrm{F}\right)$, research has focused on multilayered EBC systems that use a Si "bond coat" applied to the SiC. The design objective for the bond coat is similar to that of the aluminum-rich metallic layer used in $\mathrm{TBC}$ systems ${ }^{27}$. It serves as a sacrificial layer that forms a protective thermally grown oxide $\left(\mathrm{SiO}_{2}\right)$ upon exposure to oxidizing species, thereby inhibiting their access to the SiC-based component surface. However, volatilization of the protective oxide occurs by its reaction with water vapor to form gaseous silicon hydroxides such as $\mathrm{Si}(\mathrm{OH})_{4}$. The bond coat must therefore be covered (environmentally protected) by materials that impede the diffusion of oxygen and water vapor to the Si surface, while being highly resistant to silicon hydroxide forming reactions with water to avoid steam volatilization during engine operation. 1 , 25, 28-38

These design objectives must be achieved subject to numerous constraints. For example, the various layers of the $\mathrm{EBC}$ system must have a coefficient of thermal expansion (CTE) similar to 

range experienced during operation of a gas turbine engine. ${ }^{32,33}$ The EBC materials must be stable and thermochemically compatible so that deleterious reaction products are not formed between them or with the substrate. In addition, they must meet other demands of the engine environment which include resistance to erosion by fine (dust) particles, ${ }^{39-42}$ impact by larger foreign objects ${ }^{41-43}$ and survival of reactions with molten calcium-magnesium-aluminum-silicates (CMAS). ${ }^{44,45-48}$ Finally, when used on rotated components, EBCs will be required to sustain significant static and cyclic loads that could cause creep deformation and fracture. ${ }^{22,35-37,49-52}$ This use environment is therefore one of the most severe ever envisioned for an advanced material system.

The environmental stability, CTE, and elastic modulus of many candidate EBC materials have been reviewed. ${ }^{1,30,34,53}$ The ytterbium monosilicate $\left(\mathrm{Yb}_{2} \mathrm{SiO}_{5}\right) /$ mullite $\left(\mathrm{Al}_{6} \mathrm{Si}_{2} \mathrm{O}_{13}\right) / \mathrm{Si}$ trilayer system has received significant recent attention due to the thermochemical compatibility between its component materials and the very low steam volatility of $\mathrm{Yb}_{2} \mathrm{SiO}_{5}(\mathrm{YbMS}){ }^{53}$ However, the CTE of YbMS has been found to be substantially higher than that of SiC $\left(7.5 \times 10^{-6}\right.$ ${ }^{\circ} \mathrm{C}^{-1}$ for YbMS versus $4.7 \times 10^{-6}{ }^{\circ} \mathrm{C}^{-1}$ for $\left.\mathrm{SiC}\right) .{ }^{1,34}$ During cooling from $1316{ }^{\circ} \mathrm{C}$, this was found to result in the development of a high (biaxial) tension in the YbMS layer, which was relieved by channel (mud) cracking. ${ }^{32,33}$ The presence of cracks through the YbMS and mullite (which also has a higher $\mathrm{CTE}$ than that of $\mathrm{SiC}$ ) layers then provided oxidizing species a gas phase transport path to the $\mathrm{Si}$ bond coat, resulting in the rapid growth of a $\beta$-cristobalite $\left(\mathrm{SiO}_{2}\right)$ phase on the outer silicon surface. The thermally grown oxide (TGO) also underwent a large reduction in volume $(\sim 4.5 \%)$ during its cubic to tetragonal (inversion type) $\beta \rightarrow \alpha$ phase transformation upon cooling through $\sim 220^{\circ} \mathrm{C}$, resulting in severe TGO microcracking, loss of its oxidation protection qualities, and premature spallation of the EBC. These observations indicate that high CTE topcoat candidates (including YbMS, other rare earth silicates with high CTE, and aluminumsilicates such as mullite), are likely to be unsatisfactory for the diffusion-impeding layers of EBC systems.

Ytterbium disilicate (YbDS), a line compound in the $\mathrm{Yb}_{2} \mathrm{O}_{3}-\mathrm{SiO}_{2}$ binary phase diagram with composition $\mathrm{Yb}_{2} \mathrm{Si}_{2} \mathrm{O}_{7}$, is a promising alternate material for environmental barrier layer 

(compared to $4.7 \times 10^{-6}{ }^{\circ} \mathrm{C}^{-1}$ for $\mathrm{SiC}$ ) ${ }^{47}$. YbDS therefore satisfies one of the primary design requirements of an EBC application. However, its resistance to volatilization by reactions with water vapor is significantly less than that of its monosilicate counterpart ${ }^{53}$, and its thermochemical stability in contact with a Si bond coat has not been reported. A recent study has led to the identification of an optimized atmospheric plasma spray (APS) deposition method for applying YbDS coatings to $\mathrm{Si}$ bond coat protected $\mathrm{SiC}$ substrates. ${ }^{54}$

The objective of the preliminary study reported here is to begin an investigation of the thermomechanical and environmental response of an APS deposited YbDS/Si EBC system on a $\mathrm{SiC}$ substrate as it is subjected to thermal cycling between $110{ }^{\circ} \mathrm{C}$ and $1316{ }^{\circ} \mathrm{C}$ in a flowing steam/oxygen environment. The study reports and characterizes the growth of a TGO layer on the silicon bond coat during steam cycling for up to 2,000 hours, and estimates the diffusion coefficient of the oxidizing species through the YbDS coating. It reports and investigates the process by which the topcoat is partially volatilized during steam cycling, and explores the mechanism by which edge coating failure eventually occurs during thermal cycling in a water vapor rich environment. This EBC system is the first to be reported with sufficient resistance to volatilization and thermal cycling for an engine application.

\section{Experimental}

\subsection{Coating Deposition}

Bi-layer YbDS/Si coatings were deposited onto surface roughened $25.4 \mathrm{~mm}$ x $12.7 \mathrm{~mm}$ x 4.8 mm thick $\alpha$-SiC Hexoloy ${ }^{\mathrm{TM}}$ substrates (Saint Gobain Ceramics, Niagara Falls, NY), Figure 1. The substrate edges were first ground forming a $45^{\circ}$ chamfer to facilitate over-coating the edges of the sample where delamination most often initiates. ${ }^{32,32}$ The target thickness of the silicon layer was $50 \mu \mathrm{m}$ while that of YbDS layer was $125 \mu \mathrm{m}$. The plasma spray deposition parameters used for each layer are summarized in Table 1. The structure of as deposited and stabilization annealed YbDS layers deposited using this spray parameter combination has been recently reported by Richards et al. ${ }^{54}$ These spray parameters resulted in a dense YbDS coating with as deposited grain size of several hundred nanometers. During thermal cycling at $1316{ }^{\circ} \mathrm{C}$, this gradually increased to $\sim 5 \mu \mathrm{m}$. These spray conditions were chosen as a compromise to ensure 
deposition of low void content coatings while limiting the loss of $\mathrm{SiO}$ from the liquid droplets during transit through the plasma plume. This $\mathrm{SiO}$ loss is a result of its higher vapor pressure (compared to ytterbium containing vapor species) at the droplet temperatures encountered in plasma spray deposition. ${ }^{34}$ It results in the formation of a two phase YbDS + YbMS coating observable by a difference in gray scale contrast when imaged in the scanning electron microscope using backscattered electrons (BSE mode imaging), Figure 2(a). In the coatings studied here, the YbMS volume fraction was $~ 15 \%$, and can be seen in Figure 2(a) as elongated (ellipsoidal) regions of a lighter contrast phase oriented in the plane of the coating. YbMS precipitates can also be seen in the YbDS topcoat, Figure 2(b), consistent with prior studies of this system. ${ }^{54}$ Though the topcoat is a mixture of YbDS and YbMS, it will be referenced as the "YbDS layer" for convenience.

Table 1: Deposition parameters for air plasma spray deposition of YbDS/Si layers.

\begin{tabular}{ccccccc}
\hline \hline $\begin{array}{c}\text { APS } \\
\text { Layer }\end{array}$ & $\begin{array}{c}\text { Torch } \\
\text { Power } \\
(\mathrm{kW})\end{array}$ & $\begin{array}{c}\text { Arc } \\
\text { Current }(\mathrm{A})\end{array}$ & $\begin{array}{c}\text { Primary Ar } \\
(\mathrm{slm})\end{array}$ & $\begin{array}{c}\text { Secondary } \\
\mathrm{H}_{2}(\mathrm{slm})\end{array}$ & $\begin{array}{c}\text { Powder } \\
\text { feed rate } \\
(\mathrm{g} / \mathrm{min})\end{array}$ & $\begin{array}{c}\text { Ar carrier } \\
\text { gas flow } \\
\text { rate }(\mathrm{slm})\end{array}$ \\
\hline $\mathrm{Yb}_{2} \mathrm{Si}_{2} \mathrm{O}_{7}$ & 11.2 & 275 & 84.95 & 0.94 & $41.5 /$ lower & 5.90 \\
$\mathrm{Si}$ & 22.7 & 500 & 77.87 & 0.94 & $31.0 /$ upper & 5.90 \\
\hline \hline
\end{tabular}

The APS powders used for deposition were the same as those used in prior EBC research, ${ }^{54}$ and consisted of a specially produced stoichiometric YbDS powder (Treibacher Industrie Inc., Toronto, ON) and APS grade SL-111 Si powder (Micron Metals, Bergenfield, NJ). The YbDS powder size distribution was the same as that previously reported (from 20 to $50 \mu \mathrm{m}$ ). The $\mathrm{Si}$ powder was sieved before use to remove fine and coarse particles so that its powder diameter ranged between 70 and $110 \mu \mathrm{m}$. The spray parameters for Si deposition were adjusted to result in a low porosity Si bond coat similar to that previously reported, ${ }^{33,54}$ Table 1 . Its rough surface, Figure 2(a) and (b) was intended to improve adhesion between the two coating layers.

Both the Si and YbDS layers were deposited onto substrates placed in a box furnace held at a temperature of $1200{ }^{\circ} \mathrm{C}$. To reduce oxidation of the $\mathrm{SiC}$ and $\mathrm{Si}$ bond coat surfaces during deposition, an $\mathrm{Ar} / \mathrm{H}_{2}$ reducing gas mixture was continuously flowed through the furnace at a rate of $20 \mathrm{slm}$. After deposition of the Si layer, the reducing gas flow was terminated and the YbDS 
layer was then deposited into the furnace. The coated samples were finally stabilization annealed (to transform metastable phases) at a temperature of $1300{ }^{\circ} \mathrm{C}$ in air for 20 hours. ${ }^{1,25,28,30-34}$

\subsection{Steam Cycling}

Coated substrates were isothermally cycled in a steam-cycling furnace. The thermal cycle consisted of a $60 \mathrm{~min}$ hot $\left(1316^{\circ} \mathrm{C}\right)$ and a $10 \mathrm{~min}$ cold $\left(110{ }^{\circ} \mathrm{C}\right)$ cycle conducted within an atmospheric pressure, $90 \% \mathrm{H}_{2} \mathrm{O} / 10 \% \mathrm{O}_{2}$ gas flow with a flow speed of $4.4 \mathrm{~cm} / \mathrm{s}$ (equivalent to a volumetric flow of $4.1 \mathrm{~s} / \mathrm{m}$ ). The environment local to these substrates during steam cycling is shown in Figure 3. For the testing configuration used here, 4 samples were initially cycled simultaneously, with one being removed after 250, 500, 750 and 1000 cycles. This was followed by the testing of a fifth sample subjected to a multi-sample exposure for 500 cycles and 1500 additional cycles with just a single sample in the furnace (for a total of 2000 cycles). During steam cycling, all the samples were examined optically every 100 cycles to assess damage.

The environmental flow conditions were similar to those previously used for steam-cycling studies, ${ }^{32,33}$ and approximate the $\mathrm{H}_{2} \mathrm{O}$ partial pressure during lean hydrocarbon combustion at a pressure of $10 \mathrm{~atm}$. Saturation of $\mathrm{Si}$-bearing vapor $\left(\mathrm{Si}(\mathrm{OH})_{4}\right.$ species) can occur in this furnace arrangement. Because the steam flow speed was low, and the area of (uncoated) $\mathrm{SiC}$ exposed to the environment was large $\left(2,800 \mathrm{~mm}^{2}\right)$ when 4 samples were present, a significant $\mathrm{Si}(\mathrm{OH})_{4}$ concentration is expected from the water vapor reaction with the $\mathrm{SiO}_{2}$ scale grown on the exposed $\mathrm{SiC}$ surfaces. The recession rate of $\mathrm{SiO}_{2}$ was calculated for the conditions used here by the method of Golden and Opila, ${ }^{55}$ and found to be $44.65 \mathrm{~nm} / \mathrm{h}$. Since the surface area of $\mathrm{SiO}_{2}$ exposed to the environment was $700 \mathrm{~mm}^{2}$ per sample, $1.35 \times 10^{-9}$ moles of $\mathrm{Si}(\mathrm{OH})_{4}$ were formed every second while four samples were in the furnace. Using experimental thermochemical data for the similar Y-Si-O system, ${ }^{56}$ the equilibrium partial pressure of $\mathrm{Si}(\mathrm{OH})_{4}$, was found to be 4.97 $\mathrm{x} 10^{-6} \mathrm{~atm}$. Since the gas flow rate through the steam-cycling furnace was $4.1 \mathrm{slm}$, the $\mathrm{Si}(\mathrm{OH})_{4}$ concentration was $40 \%$ of the saturation limit with four samples in the furnace, but only $10 \%$ of the saturation limit with a single sample present. Testing the 2000 cycle sample individually for its last 1500 cycles in a low $\mathrm{Si}(\mathrm{OH})_{4}$ concentration environment then enabled the surface volatilization of the YbDS layer to be observed and characterized. The single sample 2000 cycle test was therefore intended to investigate the combined effects of steam volatilization of the 
YbDS layer and thermal cycling while the other four samples enabled study of the thermomechanical response of the EBC system and the effects of steam reactions with edge exposed TGO.

\subsection{Coating Characterization}

X-ray diffraction (XRD) measurements of the YbDS topcoat (X'Pert Pro MPD, PANalytical, Westborough, MA) were performed on some samples. These samples were sectioned, polished, and examined with a Quanta 650 field emission scanning electron microscope (FEI, Hillsboro, OR) operating in the back-scattered electron (BSE) mode. All images were collected under lowvacuum conditions. A gamma correction was applied to the images to enhance relative contrast between high and low-Z materials. ${ }^{32,54}$ Energy dispersive spectroscopy (EDS) was used for elemental microanalysis $\left(\mathrm{X}-\mathrm{Max}^{\mathrm{N}} 150 \mathrm{SDD}\right.$, Oxford Instruments, Concord, MA). EDS spectra were captured using a $10 \mathrm{kV}$ accelerating voltage and small spot size to minimize fluorescence interactions. $^{47}$

Average TGO layer thicknesses were determined from 50 different areas equally spaced across the coating cross-section. The thickness of oxide scale perpendicular to the local silicon bond coat surface of each sampled area was measured at about hundred evenly spaced locations across the coating cross-section and averaged. The standard deviation of these average oxide scale thickness was $100 \mathrm{~nm}$ or less, however, as shown later, the difference between the thinnest and thickest TGO thickness was much larger than this. It should also be noted that the measurements used to compute an average thickness were collected from locations where the TGO layer was pore-free and flat. Raman Spectroscopy, using an inVia microscope (Renishaw, Hoffman Estates, IL, was used to identify the TGO phase. ${ }^{23,24}$ Raman analyses were performed using a 50x lens with a numerical aperture of 0.5. An argon laser (488 nm) was used as the light source. Approximately $99 \%$ of the Gaussian distributed incident light of the source resided within a $1 \mu \mathrm{m}$ diameter circle on the sample, yielding a spatial resolution for this technique of $\sim 1$ $\mu \mathrm{m}$.

\subsection{Energy Release Rate and Residual Stress Calculations}


Thermomechanical analyses of coating residual stresses, and associated strain energy release rates (ERR) during debonding of the elastic coating system, were calculated using the LayerSlayer ${ }^{57}$ software package. All ERR calculations assumed that the coating layers remained elastic during cooling and ignored stress relief by mechanisms such as cracking or creep which can be significant at temperatures above $800{ }^{\circ} \mathrm{C}^{58}$ The ERR analysis was therefore similar to that previously applied to tri-layer EBC systems. ${ }^{32,33}$ The thermophysical properties and the small residual stresses calculated for this elastic coating-substrate bi-layer after cooling from the stabilization (stress free) annealing temperature of $1300{ }^{\circ} \mathrm{C}$ (before TGO growth had commenced) are listed in Table $2^{59,60,61,62,63,64,65,66,67,68}$.

Table 2: Thermophysical properties of EBC system components.

\begin{tabular}{|c|c|c|c|c|c|c|}
\hline Material & $\begin{array}{c}\mathrm{CTE} \\
\left(\times 10^{6}{ }^{\circ} \mathrm{C}^{-1}\right)\end{array}$ & $\begin{array}{l}\text { Young's } \\
\text { Modulus } \\
(\mathrm{GPa})\end{array}$ & $\begin{array}{c}\text { Poisson } \\
\text { Ratio } \\
v\end{array}$ & $\begin{array}{c}\text { Layer } \\
\text { Thickness }\end{array}$ & $\begin{array}{c}\text { Thermal } \\
\text { Residual } \\
\text { Stress }^{\mathrm{a}}(\mathrm{MPa})\end{array}$ & Application \\
\hline $\begin{array}{l}\text { YbDS } \\
E_{A P S}\end{array}$ & 4.1 & $\begin{array}{c}180^{\mathrm{b}} \\
90^{c}\end{array}$ & $0.27^{\mathrm{d}}$ & $125 \mu \mathrm{m}$ & $\begin{array}{c}-170 \\
-88\end{array}$ & Top coat \\
\hline $\begin{array}{l}\text { Cristobalite- } \alpha \\
\text { Cristobalite }-\beta\end{array}$ & $\begin{array}{r}96^{\mathrm{e}} \\
3.1^{36}\end{array}$ & $\begin{array}{l}65^{29} \\
70^{f}\end{array}$ & $\begin{array}{l}-0.164^{35} \\
-0.042^{37} \\
\end{array}$ & $0-5 \mu \mathrm{m}$ & $>4,300$ & $\begin{array}{c}\text { Oxidation } \\
\text { product }\end{array}$ \\
\hline $\begin{array}{l}\text { Silicon } \\
E_{A P S}\end{array}$ & 4.1 & $\begin{array}{c}163^{34} \\
70^{g}\end{array}$ & 0.223 & $50 \mu \mathrm{m}$ & $\begin{array}{l}-145 \\
-65\end{array}$ & Bond coat \\
\hline $\operatorname{SiC}(\alpha)$ & 4.67 & 430 & 0.14 & $4.76 \mathrm{~mm}$ & $\begin{array}{l}24 \\
12 \\
\end{array}$ & Substrate \\
\hline
\end{tabular}

${ }^{\mathrm{a}}$ Calculated using LayerSlayer and the bulk mechanical properties within the table.

${ }^{\mathrm{b}}$ Value from nanoidentation.

${ }^{\mathrm{c}} 50 \%$ reduction in modulus assumed for dense APS structure, similar to prior APS work. ${ }^{28}$ ${ }^{\mathrm{d}}$ Based on $\mathrm{Y}_{2} \mathrm{Si}_{2} \mathrm{O}_{7}{ }^{33}$

${ }^{\mathrm{e}}$ Average of values reported on the $20-200^{\circ} \mathrm{C}$ interval. ${ }^{31,32}$

${ }^{\mathrm{f}}$ Based on Young's modulus ratio of $\alpha$ and $\beta$ quartz ${ }^{30}$ and $\alpha$ cristobalite.

${ }^{\mathrm{g}}$ Value for APS material from Richards, Zhao, and Wadley. ${ }^{28}$

\section{Results}

Six low porosity YbDS on Si bi-layer coatings were deposited on $\mathrm{SiC}$ substrates using the optimized APS approach. A photograph of the coated surface of one of the samples after deposition of its coating is shown in Figure 4(a) and after stabilization annealing in Figure 4(b). The average thickness of the YbDS layer for each sample is reported in Table 3. Slight variations in thickness of the YbDS layer were observed between individual coatings and over the crosssection of a single coating. The thickness of the majority of the top coat for each sample 
generally varied within $\pm 10 \mu \mathrm{m}$ of the reported average. However, small areas of substantially thicker or thinner thickness (up to $\pm 20 \%$ of the average) were occasionally observed which is typical for an APS process. ${ }^{54}$ The thickness values reported in Table 3 are the average of fifty measurements taken normal to the substrate surface (10 values sampled from five different regions across the coating). One of the samples was used to characterize the coating composition and structure while the remainder were steam cycled between $110{ }^{\circ} \mathrm{C}$ and $1316{ }^{\circ} \mathrm{C}$.

Table 3: YbDS layer thicknesses of samples. Thicknesses range $\pm 10 \mu \mathrm{m}$.

\begin{tabular}{lccccccc}
\hline \hline $\begin{array}{l}\text { Coating } \\
\text { Condition }\end{array}$ & $\begin{array}{c}\text { As- } \\
\text { Deposited }\end{array}$ & Annealed & $\begin{array}{c}250 \\
\text { Cycles }\end{array}$ & $\begin{array}{c}500 \\
\text { Cycles }\end{array}$ & $\begin{array}{c}750 \\
\text { Cycles }\end{array}$ & $\begin{array}{c}1000 \\
\text { Cycles }\end{array}$ & $\begin{array}{c}2000 \\
\text { Cycles }\end{array}$ \\
\hline $\begin{array}{l}\text { Thickness } \\
(\mu \mathrm{m})\end{array}$ & 125 & 135 & 125 & 155 & 130 & 135 & 125 \\
\hline \hline
\end{tabular}

While edge damage was evident upon optical inspection of most samples, the damage did not appear to have affected the sample center even after 2000 cycles, Figure 4(c), and none of the coatings had spalled in locations other than the coating edges. Figure 5 shows BSE mode SEM images of the as-deposited and annealed coating cross sections, and a selection of those that had been steam cycled. Minimal changes in layer thicknesses and coating structure were apparent in these low magnification images at the coating center. Examination of these images indicated the gradual (and very minor) formation of a new TGO phase at the YbDS - Si interface, Figure 5, and the appearance of a layer of porous and microcracked material at the outer surface of the YbDS layer in the sample removed from the furnace after 2000 steam cycles, Figure 5(f).

\subsection{Thermally Grown Oxide (TGO)}

When examined by SEM in the BSE imaging mode, a darker grey phase was found at the YbDS - Si interface of all of the steam-cycled coatings, Figure 6. This dark grey phase was observed to be dense but of variable thickness in each sample. An EDS analysis of the layer revealed that it contained only $\mathrm{Si}$ and $\mathrm{O}$. Since there are 11 crystalline polymorphs of silica and two other non-crystalline phases, ${ }^{69}$ Raman analysis of the layer was performed to identify which phase had formed. The only spectral peaks present not belonging to Si had wavenumbers of 230 $\mathrm{cm}^{-1}$ and $416 \mathrm{~cm}^{-1}$, indicating the layer to be $\alpha$-cristobalite with $\mathrm{SiO}_{2}$ stoichiometry. ${ }^{70-72}$ This $\alpha$ cristobalite had presumably formed as $\beta$-cristobalite at $1316{ }^{\circ} \mathrm{C}$ and transformed on cooling through $220{ }^{\circ} \mathrm{C}$ to the $\alpha$ phase. Cristobalite has previously been identified as the TGO phase 
formed upon a Si bond coat during thermal cycling at this temperature, ${ }^{32,33}$ and on $\mathrm{SiC}$ oxidized at comparable temperatures, ${ }^{2,73}$ even though it is not the equilibrium phase at this temperature. ${ }^{74}$ The $\mathrm{Yb}_{2} \mathrm{O}_{3}-\mathrm{SiO}_{2}$ phase diagram relevant to this $\mathrm{EBC}$ system has only four stoichiometric phases at temperatures up to the YbDS melting point $\left(1650{ }^{\circ} \mathrm{C}\right)$ : YbDS, YbMS, and the two terminal oxides. ${ }^{75}$ This indicates that there is no mixing of $\mathrm{Yb}_{2} \mathrm{Si}_{2} \mathrm{O}_{7}$ and $\mathrm{SiO}_{2}$ at temperatures up to $\sim 1650{ }^{\circ} \mathrm{C}$, and it is therefore concluded that the $\mathrm{Yb}_{2} \mathrm{Si}_{2} \mathrm{O}_{7}-\mathrm{SiO}_{2}$ interface is thermochemically stable, in agreement with prior determinations. ${ }^{76}$

Examination of Figure 6 indicates that the average thickness of the thermally grown oxide (TGO) increased with high temperature exposure time, reaching a thickness of a few micrometers after 2000 steam cycles. The TGO was dense and adherent in all samples. The average measured thickness, $h$ ' of the TGO near the center of the steam-cycled samples is plotted as a function of hot exposure time (number of cycles times $1 \mathrm{hr}$ ) in Figure 7(a). The measured oxide thickness depended upon accumulated time, and h'(t) at $1316^{\circ} \mathrm{C}$ could be well fitted to a linear relation: $\mathrm{h}^{\prime}(\mathrm{t})=\mathrm{h}_{\mathrm{o}}+k_{l} \mathrm{t}$ where the linear rate constant $k_{l}=1.2 \mathrm{~nm} / \mathrm{h}$ and $\mathrm{h}_{\mathrm{o}}=140 \mathrm{~nm}$. This $\mathrm{h}_{\mathrm{o}}$ value agreed with other observations of annealed coatings (not shown) that had a TGO thickness before steam cycling of 100-200 nm.

Careful examination of the TGO layer of the sample exposed to 2000 steam cycles, Figures 6(d) and 8(a) shows that it contained closely $(\sim 2 \mu \mathrm{m})$ spaced vertical (channel type) cracks that fully penetrated the oxide layer. Occasionally, one of these cracked segments had also delaminated from the underlying Si layer, especially in regions where the local TGO thickness varied, Figure 8(a). Channel type cracking of the TGO was also observed in the sample exposed to 1000 steam cycles, Figure 8(b), but to a much lesser extent than the 2000 cycle sample. This channel cracking was only observable in the SEM in samples exposed to 1000 or 2000 steamcycles whose TGO thicknesses were $1 \mu \mathrm{m}$ or more. The separation distance between the crack faces was measured to be in the range of 3-10 nm implying that the crack face separations accommodated an inplane equivalent strain (500 cracks per mm x $5 \mathrm{~nm} /$ per crack) of $0.25 \%$. 


\subsection{YbDS Volatilization}

The 2000 steam-cycle topcoat was observed to have suffered from surface reaction with the steam environment, Figure 5(f). X-ray Mass Attenuation Coefficients ${ }^{77}$ indicate the maximum depth of penetration of $45 \mathrm{kV}$ X-rays is $\sim 75 \mu \mathrm{m}$ for YbDS and $\sim 56 \mu \mathrm{m}$ for YbMS. Since the majority of the diffracted signal in an XRD experiment therefore originates from a region within a depth of $20 \mu \mathrm{m}$ from the surface, XRD is a suitable technique for a phase analysis of the surface volatilized region. Figure 9 shows an XRD pattern of the surface of the sample subjected to 2000 cycles and compares it to that of a sample in the annealed condition. All indexed peaks could be attributed to one of three phases previously identified in this system. ${ }^{54}$ The XRD patterns for the thermally cycled surface indicated a significant increase in the volume fraction of (the I2/a structure) YbMS phase which was present in addition to (the $\mathrm{C} 2 / \mathrm{m}$ structure) YbDS. Only a trace amount of a metastable (P21/c structure) YbMS phase was identified.

Figure 10(a) shows a higher magnification BSE image of the cross sectional surface of a steam volatilized YbDS region: the environmentally attacked YbDS layer was 5-15 $\mu \mathrm{m}$ thick. Yb and Si EDS dot maps are presented in Figure 10(b) and (c). These dot maps and the lighter surface BSE contrast indicate an increased $\mathrm{Yb}$ (and reduced $\mathrm{Si}$ ) content in the surface volatilized layer compared to the unaffected material below. Based upon the crystallographic identification of only YbMS and YbDS by XRD and the differences in Yb and Si content indicated by EDS, this surface volatilized layer was identified as predominantly YbMS, consistent with steam jet studies. $^{78}$

Figure 11 shows three higher magnification BSE mode SEM images of the 2000 cycle sample surface. They show that the surface layer had also become porous. The pores had roughly circular cross sections but were long in length, and many were connected to the surface of the coating. The porosity of this surface layer, and reduced $\mathrm{SiO}_{2}$ content when compared to the asdeposited topcoat, are consistent with loss of $\mathrm{SiO}_{2}$ from the YbDS layer during steam cycling, leaving YbMS that has exhibited a greater resistance to volatilization. ${ }^{30,78}$ These observations suggest that a YbDS topcoat might be able to provide better than anticipated environmental protection under the test conditions used here. 
Several forms of mechanical damage are evident in the sample surface exposed to 2000 hours of flowing steam and oxygen at $1316{ }^{\circ} \mathrm{C}$, Figure 11 . Some areas underwent vertical cracking of the adherent, but porous YbMS surface layer, Figure 11(a), with very large crack opening displacement. In other areas, Figure 11(b), delamination cracks had resulted in spalling of the compositionally modified surface region. Elsewhere, channel cracks propagated deeply into the unaffected YbDS region and intersected a delamination crack within the unaffected YbDS region, Figure 11(c). The damage was consistent with inplane shrinkage due to $\mathrm{SiO}_{2}$ loss and residual stresses that arise upon cooling; a consequence of the large CTE mismatch between $\operatorname{YbMS}\left(7.5 \times 10^{-6}{ }^{\circ} \mathrm{C}^{-1}\right)$ and the $\operatorname{YbDS}\left(4.1 \times 10^{-6}{ }^{\circ} \mathrm{C}^{-1}\right) .{ }^{33}$

\subsection{Edge Delamination}

Only the edges of the coatings were observed to undergo delamination, the severity of which increased with exposure time as shown in Figure 12. It was manifested as a lifting-off of the coating edge. This edge delamination occurred despite attempts to extend the coating over the sides of the substrate by chamfering the corners, as can be seen in Figure 12(a). The edge failure mode began with oxidation of the thin Si bond coat at the side of the substrates forming the darker gray TGO phase that can be seen with BSE imaging, Figure 12(b). EDS and Raman analyses of this dark gray phase confirmed it to be $\alpha$-cristobalite $\left(\mathrm{SiO}_{2}\right)$. This edge $\mathrm{SiO}_{2}$ layer underwent rapid steam volatilization and mechanical spallation, Figure 12(c). As this consumed the Si bond coat at the edge of the samples, it allowed the YbDS layer to bend away from the substrate surface. The distance of oxygen penetration from the sides of the sample, and therefore lateral distance of TGO growth and coating delamination from the edge of the sample all increased with accumulation of steam cycles. After 2000 cycles, the coating showed a reverse curvature, Figure 12(d).

\section{Discussion}

The results presented above indicate that the use of an APS deposited bilayer Si/YbDS EBC provided up to 2000 hours of protection from volatilization during steam cycling between $110^{\circ}$ and $1316^{\circ} \mathrm{C}$ in an atmospheric pressure, $90 \% \mathrm{H}_{2} \mathrm{O} / 10 \% \mathrm{O}_{2}$ environment. The YbDS layer impeded the transport of oxidizing species to the Si bond coat resulting in slow TGO layer 
thickening. Prolonged thermo-cyclic testing in slowly flowing steam containing a low partial pressure of $\mathrm{Si}(\mathrm{OH})_{4}$ resulted in the gradual loss of $\mathrm{SiO}_{2}$ from the outer surface of the YBDS top coat accompanied by its conversion to YbMS. There was no evidence of residual stress driven channel cracking or delamination of the coating system, consistent with the good CTE matching in the substrate coating system. However, significant edge delamination was observed which slowly advanced inwards from the periphery of the substrates. This edge delamination was initiated by oxidation of the environment exposed bond coat at the sides of the test coupons, and was aided by the development of a bending moment in the coating as the YbDS outer surface was converted to YbMS with a significantly higher CTE coefficient.

\subsection{Oxide growth at the bond coat surface}

After 2000 hours of steam and oxygen exposure at $1316^{\circ} \mathrm{C}$, the thickness of the cristobalite TGO oxide layer formed in the $\mathrm{YbDS} / \mathrm{Si}$ system had only reached $2.5 \mu \mathrm{m}$. This contrasted sharply with similar studies of YbMS protected silicon layers on the same substrate where TGO thicknesses of 15-150 $\mu \mathrm{m}$ (depending upon the coating structure) were observed after less than 400 hours of identical environmental exposure. ${ }^{32,33}$ In the YbMS coated system, very rapid oxidation occurred because channel cracks fully penetrated the YbMS layer and arrested in the silicon bond coat. This provided a very rapid, gas-phase transport path for both oxygen and $\mathrm{H}_{2} \mathrm{O}$ vapor to the silicon surface. Deal and Grove ${ }^{79}$ have shown that the rate of TGO growth rate on silicon was much higher for $\mathrm{H}_{2} \mathrm{O}$ than dry $\mathrm{O}_{2}$. The slow TGO growth rate observed far from the sample edges of the channel crack free YbDS coated samples indicates that solid-state diffusional transport of the oxidizing species through the YbDS layer governed the rate of oxidation of the Si bond coat surface. Since there has been little experimental study of the transport kinetics of candidate oxidizing species $\left(\mathrm{H}_{2} \mathrm{O}, \mathrm{OH}^{-}\right.$or $\left.\mathrm{O}^{2-}\right)$ in rare earth silicates, we illustrate our estimation of the diffusivity of the oxidant by taking it to be $\mathrm{O}^{2-}$ (formed by the surface dissociation of $\mathrm{O}_{2}$ ). Its most likely transport path would be via grain boundaries since the grain diamter of the YbDS is small (several hundred nanometers after deposition to $\sim 5 \mu \mathrm{m}$ after environmental exposure for 2,000 hours, Figure 6(d)).

The silica TGO thicknesses measured here, Figure 7(a), were obtained from samples of slightly differing YbDS thicknesses, Table 3. To compensate for this, the data has been corrected 
to that for a constant YbDS layer thickness of $100 \mu \mathrm{m}$. Since there exists constant oxygen partial pressure at the environment/YbDS and $\mathrm{YbDS} / \mathrm{SiO}_{2}$ interfaces, diffusion can be modeled by the one-dimensional form of Fick's First Law. The flux of the oxidizing species, $J(x)$, that passes through a plane in the YbDS layer a distance $x$ below the outer surface of the layer depends upon the (unknown) oxygen YbDS diffusion coefficient, $D_{O}$, and the gradient in concentration of the oxidant:

$$
J(x)=-D_{O} d c / d x
$$

where $c$ is the concentration of the oxidizer (presumed here to be oxygen anions).

The partial pressure of $\mathrm{O}_{2}$ at the exterior sample surface during steam cycling was $0.1 \mathrm{~atm}$. Using the ideal gas law, this partial pressure can be converted to an oxygen concentration (number of moles of $\mathrm{O}_{2}(n)$ per unit volume, $\mathrm{V}$ );

$$
\frac{n}{V}=\frac{P}{R T}=\frac{0.1 \mathrm{~atm}}{0.0821 \mathrm{l} \cdot \mathrm{atm} /(\mathrm{mole} \cdot \mathrm{K}) \times 1589 \mathrm{~K}}=0.767 \mathrm{~mole} / \mathrm{m}^{3}
$$

where $\mathrm{P}$ is the $\mathrm{O}_{2}$ partial pressure, $\mathrm{R}$ the Universal gas constant and $\mathrm{T}$ the absolute temperature. The oxygen partial pressure at the $\mathrm{YbDS}-\mathrm{SiO}_{2}$ interface is established by local thermochemical equilibrium, and was calculated, using the FactSage software program, ${ }^{80}$ to be $4.29 \times 10^{-10}$ atm at $1316^{\circ} \mathrm{C}$. The concentration of oxygen anions at the bond coat surface was therefore very small compared to that at the outer surface. If $D_{O}$ is constant throughout the YbDS coating, this implies that the oxidizing flux, $J(x)$ reaching a growing $\mathrm{SiO}_{2}$ layer is inversely related to the thickness of the YbDS layer through which it has diffused. If all this flux was consumed in silica formation, the TGO thickness will vary inversely with the thickness of the diffusion barrier. The topcoat thickness therefore provides a practical means for controlling the rate of growth of the TGO layer.

This observation also enables the thickness of the TGO layer as a function of time, h'( $t$ ) for samples with variable thickness diffusion barriers (observed here), to be related to that for a diffusion barrier of constant thickness, $\mathrm{h}(\mathrm{t})$ by:

$$
h(t)=h^{\prime}(t) \frac{x_{\text {meas }}}{x_{\text {tar }}}
$$


where $x_{\text {meas }}$ is the measured YbDS thickness that gave h'( $\left.\mathrm{t}\right)$ and $x_{\text {tar }}$ is the target YbDS thickness that gives $h(t)$. Each measured TGO thickness, h'(t) has been adjusted using Equation (2) to that for a $100 \mu \mathrm{m}$ YbDS layer thickness $\left(x_{t a r}=100 \mu \mathrm{m}\right)$, and these values have been plotted as a function of oxidation time in Figure 7(b). The silica layer thickness remained linearly related to the oxidation time, but with a slightly altered linear rate constant $k_{l}=1.44 \mathrm{~nm} / \mathrm{h}$.

It is also possible to make a preliminary estimate the oxygen diffusion coefficient, $D_{O}$ in the YbDS layer. If $m_{O}$ is the mass of the oxygen ions that diffuse through the YbDS per unit area per unit time, and if $M_{O}$ is the molar mass of oxygen atoms, the oxygen flux incident upon the TGO surface is:

$$
J_{O} \equiv \dot{m}_{O} / M_{O}
$$

If $\dot{\Gamma}_{\mathrm{SiO}_{2}}$ is the TGO growth rate (in mass per unit area per unit time) and $2 \mathrm{M}_{\mathrm{O}} / \mathrm{M}_{\mathrm{SiO}_{2}}$ the mass fraction of oxygen anions in $\mathrm{SiO}_{2}$, the mass of oxygen ions that diffuse through the $\mathrm{YbDS}$ per unit area per unit time is;

$$
\dot{m}_{O}=\dot{\Gamma}_{\mathrm{SiO}_{2}} * 2 \mathrm{M}_{\mathrm{O}} / \mathrm{M}_{\mathrm{SiO}_{2}}
$$

Since the TGO mass growth rate is simply the linear growth rate of the TGO, $k_{l}$, multiplied by the density of cristobalite, $\rho_{c}$, combining Equations (3) and (4) gives the oxygen flux incident upon the TGO surface;

$$
J_{O}=\left(k_{l} * \rho_{c} * 2 / M_{\mathrm{SiO}_{2}}\right)
$$

Substituting $k_{l}$ from the experiments into Equation (5) and using handbook values for the density and molar mass of cristobalite gives the oxygen flux incident upon the TGO:

$$
J_{O}=\frac{1.44 * 10^{-9} \mathrm{~m}}{3600 \mathrm{~s}} \times 2.34 \times 10^{6} \mathrm{~g} / \mathrm{m}^{3} \times \frac{2}{60 \mathrm{~g} / \mathrm{mole}}=3.12 \times 10^{-8} \mathrm{~mole} /\left(\mathrm{m}^{2} \cdot \mathrm{s}\right)
$$

From Equation (1), the concentration gradient of the oxygen ions across a $100 \mu \mathrm{m}$ thick YbDS layer is:

$$
\frac{d c}{d x}=\frac{2 \times 0.767 \mathrm{~mole} / \mathrm{m}^{3}}{100 \times 10^{-6} \mathrm{~m}}=1.534 \times 10^{4} \mathrm{~mole} / \mathrm{m}^{4}
$$




\subsection{Steam volatilization of YbDS Surface}

The exposure of $\mathrm{YbDS}$ to $\mathrm{H}_{2} \mathrm{O}$ vapor at $1316{ }^{\circ} \mathrm{C}$ in a low $\mathrm{Si}(\mathrm{OH})_{4}$ concentration environment has resulted in the formation of a porous YbDS surface layer. The origin of the porosity in the environmentally affected surface layer is consistent with $\mathrm{SiO}_{2}$ (mass) loss from the YbDS layer by formation gaseous $\mathrm{Si}(\mathrm{OH})_{4}$ leaving behind a reduced volume region of $\mathrm{YbMS}$. If $\mathrm{Yb}$ is assumed to exhibit no volatility, the resulting volume reduction during conversion of YbDS to YbMS is $26 \%$. Since the coating is laterally constrained, this volume reduction (under a state of biaxial tension in a material of very low creep strength ${ }^{58}$ ) has resulted in a porous surface layer. The initial stage of this creep enabled pore formation mechanism is schematically illustrated in Figure 13(a). As exposure continues, the pores resulting from $\mathrm{SiO}_{2}$ volatilization grow into the coating extending the open porous structure. Volatilization can then occur by a gas path diffusional route involving simultaneous transport of water vapor into, and $\mathrm{Si}(\mathrm{OH})_{4}$ out of the coating. The close spacing of the tunneling pores is such that the solid-state diffusion distance to convert the YbDS to YbMS is small, Figure 13(b).

\subsection{Delamination Energy Release Rate}

The various fracture processes observed in the $\mathrm{YbDS} / \mathrm{Si}$ system are at first surprising since there are very small differences between the CTE of the substrate, silicon and YbDS layers in this system, Table 2. As a result, the elastic residual stresses needed to drive delamination and other fracture processes are small. However, the formation of a $\beta$-phase cristobalite $\mathrm{SiO}_{2}$ layer at 

after the $\beta$ to $\alpha$ transformation upon cooling through $220^{\circ} \mathrm{C} .{ }^{32,33}$ The strain energy release rates (ERRs) available to drive the growth of delamination cracks have been estimated for each of the interfaces in this system using the LayerSlayer technique ${ }^{57}$ and the thermophysical data in Table 2. They are plotted as a function of the fraction of the $\mathrm{Si}$ bond coat converted to $\mathrm{SiO}_{2}$ and equivalent TGO thickness in Figure 14. The ERR calculations were performed using both the Young's elastic modulus of fully dense $\left(\mathrm{E}_{\mathrm{Bulk}}\right) \mathrm{YbDS}$ and a modulus reduced to $50 \%$ of this value $\left(\mathrm{E}_{\mathrm{APS}}\right)$ typical of low porosity APS materials. ${ }^{59,82-86}$ For $\mathrm{Si}$, the calculations used the polycrystalline bulk elastic modulus and a recent measured elastic modulus for a porous APS deposited Si bond coat. ${ }^{59}$ Figure 14(a) uses the elastic moduli of fully dense coating layers while Figure 14(b) uses the lower moduli for the Si and YbDS layers given in Table 2. The APS coatings investigated here are expected to lie between these two bounding sets of calculations. These energy release rates are 1-2 orders of magnitude lower than those calculated for the $\mathrm{YbMS} / \mathrm{Al}_{6} \mathrm{Si}_{2} \mathrm{O}_{13} / \mathrm{Si}$ tri-layer EBC system, ${ }^{32,33}$ which is consistent with the significantly better delamination resistance of the YbDS system.

In the as-deposited and the annealed states, the TGO layer was very thin, and the ERR calculated for all interfaces in the system were below $13 \mathrm{~J} / \mathrm{m}^{2}$ using bulk elastic moduli, Figure 14(a), and below $8 \mathrm{~J} / \mathrm{m}^{2}$ for APS-like elastic modulus. During steam cycling the TGO thickness increased (at the original YbDS - Si interface), the ERR for delamination of the $\mathrm{YbDS}$ on $\mathrm{SiO}_{2}$ interface remained almost constant, independent of the TGO thickness. This arose because the strain released by the YbDS layer (when freed from the underlying system) was very low since there is a good CTE match between Si and SiC, and the TGO layer had only a slight effect upon the strain energy that remained stored in the portion of the system that was still attached to the substrate. Comparison of Figure 14(a) and (b) shows that the ERR for delamination at the $\mathrm{SiO}_{2-}$ YbDS interface decreased by a factor of two when the bulk elastic moduli were replaced by the lower elastic moduli.

It is interesting to note that growth of the TGO initially decreased the driving force for failure at the $\mathrm{SiC}-\mathrm{Si}$ and $\mathrm{Si}-\mathrm{SiO}_{2}$ interfaces, consistent with the excellent delamination resistance exhibited during the steam cycling experiments. The reason for this is that upon delamination, 
the tensile stresses in the oxide compress the YbDS layer in the delaminated state, implying that less of its strain energy in the intact state is released during delamination. (Conversely, the YbDS layer acts to retain a portion of the oxide stress in the delaminated state, such that not all of the oxide's strain energy is released by delamination).

This mechanism for reduction in ERR, in which the strain energy in the delaminated bilayer is maintained to permit less energy to be released from the intact state, has been previously elucidated in a theoretical study of a different system. ${ }^{87}$ This mechanism relied critically on the relative thickness of the layers, and the CTE mismatch between all layers. In the present case, as the oxide layer thickness grows, the balance of compressive and tensile energy in the delaminated bilayer is lost, and the release of strain energy in the TGO dominates the behavior.

The importance of the relative bending and stretching stiffness of the delaminated bilayer is highlighted in the results for the APS system; decreasing the modulus of the YbDS decreases the initial value of the energy release rates (by a factor of two, as expected), but then proves less effective in maintaining strain energy in the delaminated state. That is, a topcoat with a lower modulus is less effective in retaining strain energy in the TGO after delamination, leading to larger energy release rates. It is also clear that if the TGO undergoes channel cracking before delamination, this provides a mechanism for partial relief of its tensile stress, resulting in a reduction in the changes to the ERR seen in Figure 14.

\subsection{TGO channel cracking}

Channel cracking of the TGO as its thickness increased could be seen in Figure 6. Vlassak has calculated the strain energy release rate $\left(G_{S S}\right)$ during steady state channel cracking of a thin coating, ${ }^{88}$ using a method developed by Bueth ${ }^{89}$ and showed that;

$$
G_{S S}=\frac{\pi \sigma^{2} t\left(1-v^{2}\right)}{2 E} g(\alpha, \beta, \eta)
$$


where $\sigma$ is the layer stress, t the thickness, $v$ is Poisson's ratio, and $E$ the elastic modulus of the TGO layer. The function $g$ represents the crack opening displacement in terms of the Dundurs parameters $(\alpha, \beta)$.

The measured TGO-channel crack opening displacement for a $t=1.5 \mu \mathrm{m}$ thick TGO was of 3$10 \mathrm{~nm}$ (Section 3.1). Using mechanical properties presented in Table 2, $G_{S S}$ ranges from $6.8 \mathrm{~N} / \mathrm{m}$ for a $3 \mathrm{~nm}$ crack opening displacement to $22.5 \mathrm{~N} / \mathrm{m}$ for a $10 \mathrm{~nm}$ crack-opening dimension at a TGO thickness of $1.5 \mu \mathrm{m}$. By comparison, the critical strain energy for cracking, $G_{I C}$ for $\alpha$ cristobalite has been estimated to lie in the range of 7.1-7.7 N/m. ${ }^{90}$ Therefore, channel cracking of the TGO becomes energetically favorable for TGO thicknesses exceeding $\sim 1.5 \mu \mathrm{m}$. This is in reasonable agreement with the dependence of the onset TGO channel cracking upon TGO thickness (exposure time) reported in Section 3.1, and is consistent with the absence of delamination other than at the edges of the coatings in any of the steam cycling experiments.

\subsection{Edge Delamination}

The tests conducted here used samples that were coated on only one side. As a result, the edges of the coatings were exposed to the steam environment during testing. Delamination of the coating was observed to progress from these regions, Figure 12. There are two processes contributing to edge delamination and the upward bending of the delaminated coating schematically, Figure 15. The first was oxidation of surface exposed silicon to form $\mathrm{SiO}_{2}$ which incurs more than a $100 \%$ volume increase. ${ }^{32,33}$ TGO was first formed at the edge of the sample where the silicon bond coat was in direct contact with the water vapor rich environment, Figure 15(a). Deal and Grove ${ }^{79}$ have shown that the oxidation rate of silicon in steam is much faster than of dry oxygen, and this appears to have resulted in the very rapid edge surface oxidation observed here, Figure 12. Examination of Figure 12(d), shows that the entire silicon bond coat was oxidized and steam volatilized after a 2000 hour exposure at $1316{ }^{\circ} \mathrm{C}$.

As oxide growth advanced inwards from the coating edge, the dilation associated with the formation of $\mathrm{SiO}_{2}$ acted as a wedge inserted at the interface between the $\mathrm{Si}$ and YbDS layers, Figure 15(b). As this wedge extended laterally along the Si bond coat, the YbDS topcoat above was subjected to a bending load which was partially relieved by creep deformation (since YbDS 


\section{Conclusions}

YbDS/Si bi-layer EBCs were deposited onto SiC substrates using a previously optimized APS approach. Five samples were isothermally steam cycled in a slowly flowing $90 \% \mathrm{H}_{2} \mathrm{O} / 10$ $\% \mathrm{O}_{2}$ environment using $60 \mathrm{~min}$ hot $\left(1316^{\circ} \mathrm{C}\right)$ and $10 \mathrm{~min}$ cold $\left(110^{\circ} \mathrm{C}\right)$ cycle. It was found that:

a) Dense APS deposited bi-layers consisting of $125 \mu \mathrm{m}$ thick nominally YbDS (actually YbDS + 15 vol\% YbMS) on a $50 \mu \mathrm{m}$ thick Si bond coat have been found to environmentally protect the underlying silicon carbide well during isothermal steamcycling to $1316^{\circ} \mathrm{C}$ for 2000 cycles.

b) The Si bond coat exhibited linear oxidation kinetics with a linear rate constant of 1.44 $\mathrm{nm} / \mathrm{h}$ for up to 2000 -hour exposures to steam at $1316{ }^{\circ} \mathrm{C}$ in a bi-layer system whose topcoat diffusion barrier layer was $100 \mu \mathrm{m}$ thick.

c) The oxygen diffusion coefficient for the YbDS layer at $1316^{\circ} \mathrm{C}$ was calculated from TGO thickening kinetics to be $D_{O}=2 \times 10^{-12} \mathrm{~m}^{2} \mathrm{~s}^{-1}$, and agreed well with the oxygen diffusion coefficients for other complex oxides at this temperature.

d) Linear bond coat oxidation to form microcrack-free cristobalite has been estimated to terminate at a TGO thickness of $\sim 300 \mathrm{~nm}$ whereupon the growth rate would transition to 

channel cracking was observed providing diffusive short-circuits through the scale and extending the linear oxidation regime indefinitely.

e) The estimated ERR for delamination in the system were predicted to remain below 20 $\mathrm{N} / \mathrm{m}$ for cristobalite scales up to $5 \mu \mathrm{m}$ in thickness (twice that after 2000 cycles of oxidation), consistent with good adherence of the bi-layer coating far from its edges.

f) Oxidation of the bond coat at the edge of the samples initiated delamination cracking at the bond coat- YbDS interface. This damage progressed towards the interior of the samples as the number of cycles increased due to a combination of TGO microfracture and steam volatilization of the surface connected TGO layer.

g) Loss of $\mathrm{SiO}_{2}$ from an approximately $15 \mu \mathrm{m}$ thick surface layer of the YbDS layer was observed after prolonged steam cycling at $1316{ }^{\circ} \mathrm{C}$ in lower $\mathrm{Si}(\mathrm{OH})_{4}$ partial pressure test environments. This was accompanied by the formation of creep-enabled voids that, in combination with channel cracks, relieved the significant shrinkage stress associated with $\mathrm{SiO}_{2}$ loss.

The dense YbDS/Si bi-layer EBCs deposited in this study had excellent steam-cycling durability while providing total aerial coverage. This combination of attributes indicates that the system may be a viable option for some isothermal applications up to $1316{ }^{\circ} \mathrm{C}$. Further analysis of mechanical properties and the effect of thermal gradients would be necessary to assess the viability of the system for use in rotating and internally cooled applications.

\section{Acknowledgements}

The authors are grateful to Elizabeth Opila and Hengbei Zhao of the University of Virginia and Bryan Harder of the NASA Glenn Research Center for helpful discussions of various aspects of this research. This work was supported by the Office of Naval Research under grants N0001411-1-0917 (HNGW/BTR) and N00014-13-1-0859 (MRB) managed by Dr. David Shifler.

\section{References}

1 K. N. Lee, "Protective Coatings for Gas Turbines." in The Gas Turbine Handbook. Edited by R. Dennis. United States Department of Energy (DOE), 2006. 
2 E. J. Opila, "Variation of the Oxidation Rate of Silicon Carbide with Water-Vapor Pressure," Journal of the American Ceramic Society, 82 625-36 (1999).

3 E. J. Opila, "Oxidation and Volatilization of Silica Formers in Water Vapor," Journal of the American Ceramic Society, 86 1238-48 (2003).

4 E. J. Opila, D. S. Fox, and N. S. Jacobson, "Mass Spectrometric Identification of Si-O-H(g) Species from the Reaction of Silica with Water Vapor at Atmospheric Pressure," Journal of the American Ceramic Society, 80 1009-12 (1997).

5 E. J. Opila and R. E. Hann Jr., "Paralinear Oxidation of CVD SiC in Water Vapor," Journal of the American Ceramic Society, 80 197-205 (1997).

6 E. J. Opila, J. L. Smialek, R. C. Robinson, D. S. Fox, and N. S. Jacobson, "SiC Recession Caused by $\mathrm{SiO} 2$ Scale Volatility under Combustion Conditions: II, Thermodynamics and Gaseous-Diffusion Model," Journal of the American Ceramic Society, 82 1826-34 (1999).

7 B. N. Cox and F. W. Zok, "Advances in ceramic composites reinforced by continuous fibers," Current Opinion in Solid State and Materials Science, 1[5] 666-73 (1996).

8 F. E. Heredia, J. C. McNulty, F. W. Zok, and A. G. Evans, "Oxidation Embrittlement Probe for Ceramic-Matrix Composites," Journal of the American Ceramic Society, 78[8] 2097-100 (1995).

9 T. E. Steyer, F. W. Zok, and D. P. Walls, "Stress rupture of an enhanced nicalon/silicon carbide composite at intermediate temperatures," Journal of the American Ceramic Society, 81[8] 2140-46 (1998).

10 L. U. Ogbuji, "Pest-resistance in SiC/BN/SiC composites," Journal of the European Ceramic Society, 23[4] 613-17 (2003).

11 L. U. J. T. Ogbuji, "Oxidative pest degradation of Hi-Nicalon/BN/SiC composite as a function of temperature and time in the burner rig," pp. 105 in 23nd Annual Conference on Composites, Advanced Ceramics, Materials, and Structures-B: Ceramic Engineering and Science Proceedings. Vol. 230. (2009).

12 K. J. LaRochelle and G. Morscher, "Tensile Stress Rupture Behavior of a Woven Ceramic Matrix Composite in Humid Environments at Intermediate Temperature-Part I," Applied Composite Materials, 13[3] 147-72 (2006).

13 R. A. Miller, "Current status of thermal barrier coatings -- An overview," Surface and Coatings Technology, 30[1] 1-11 (1987).

14 H. Zhao, Z. Yu, H.N.G. Wadley, "The Influence of Coating Compliance on the Delamination of Thermal Barrier Coatings", Surface and Coatings Technology, 204, p. 2432-2441 (2010).

15 M. R. Begley and H.N.G. Wadley, "Delamination Resistance of Thermal Barrier Coatings Containing Embedded Ductile Layers", Acta Materialia, 60, p. 2497-2508 (2012).

16 S. Krämer, J. Yang, C.G. Levi, J. Am. Ceram. Soc. 91, 576-583 (2008).

17 H. Zhao, C. G. Levi, H.N.G. Wadley, "Molten Silicate Interactions with Thermal Barrier Coatings", Surface and Coatings Technology, 251, p. 74-86 (2014)

18 H. Zhao, F. Yu, T. D. Bennett, H.N.G. Wadley, "Morphology and Thermal Conductivity of Yittria Stabilized Zirconia Coatings", Acta Materialia, 54, p.5195-5207 (2006).

19 M. Yoshiba, K. Abe, T. Aranami, and Y. Harada, "High-temperature oxidation and hot corrosion behavior of two kinds of thermal barrier coating systems for advanced gas turbines," J Therm Spray Tech, 5[3] 259-68 (1996).

20 D. R. Clarke, M. Oechsner, and N. P. Padture, "Thermal-barrier coatings for more efficient gas-turbine engines," MRS Bulletin, 37[10] 891-98 (2012). 
21 R. Darolia, "Thermal barrier coatings technology: critical review, progress update, remaining challenges and prospects," International materials reviews, 58[6] 315-48 (2013).

22 N. P. Padture, M. Gell, and E. H. Jordan, "Thermal Barrier Coatings for Gas-Turbine Engine Applications," Science, 296[5566] 280-84 (2002).

23 A. G. Evans, D. R. Mumm, J. W. Hutchinson, G. H. Meier, and F. S. Pettit, "Mechanisms controlling the durability of thermal barrier coatings," Progress in Materials Science, 46[5] 505-53 (2001).

24 J. Kimmel, N. Miriyala, J. Price, K. More, P. Tortorelli, H. Eaton, G. Linsey, and E. Sun, "Evaluation of CFCC liners with EBC after field testing in a gas turbine," Journal of the European Ceramic Society, 22 2769-75 (2002).

25 K. N. Lee, "Current status of environmental barrier coatings for Si-Based ceramics," Surface and Coatings Technology, 133-134 1-7 (2000).

26 K. N. Lee, "Key Durability Issues With Mullite-Based Environmental Barrier Coatings for SiBased Ceramics," Journal of Engineering for Gas Turbines and Power, 122 632-36 (2000).

27 Z. Yu, K.P. Dharmasena, D.D. Hass, H.N.G. Wadley,'Vapor Deposition of Platinum Alloyed Nickel Aluminide Coatings", Surface and Coatings Technology, 201, p.2326-2334,(2006).

28 B. J. Harder, J. D. Almer, C. M. Weyant, K. N. Lee, and K. T. Faber, "Residual Stress Analysis of Multilayer Environmental Barrier Coatings," Journal of the American Ceramic Society, 92 452-59 (2009).

29 K. N. Lee, J. I. Eldridge, and R. C. Robinson, "Residual Stresses and Their Effects on the Durability of Environmental Barrier Coatings for SiC Ceramics," Journal of the American Ceramic Society, 88 3483-88 (2005).

30 K. N. Lee, D. S. Fox, and N. P. Bansal, "Rare earth silicate environmental barrier coatings for $\mathrm{SiC} / \mathrm{SiC}$ composites and Si3N4 ceramics," Corrosion of Ceramic Matrix Composites, 25 1705-15 (2005).

31 K. N. Lee, D. S. Fox, J. I. Eldridge, D. Zhu, R. C. Robinson, N. P. Bansal, and R. A. Miller, "Upper Temperature Limit of Environmental Barrier Coatings Based on Mullite and BSAS," Journal of the American Ceramic Society, 86 1299-306 (2003).

32 B. T. Richards, M. R. Begley, and H. N. G. Wadley, "Mechanisms of Ytterbium Monosilicate/Mullite/Silicon Coating Failure during Thermal Cycling in Water Vapor," Journal of the American Ceramics Society, p. 1-10, (2015).

33 B. T. Richards, S. Sehr, Foucault de Franqueville, M. R. Begley, and H. N. Wadley, " Delamination of Ytterbium Monosilicate/Mullite/Silicon Coated SiC During Thermal Cycling in Water Vapor", Acta Materiala, Inpress (2015).

34 B. T. Richards and H. N. G. Wadley, "Plasma spray deposition of tri-layer environmental barrier coatings," Journal of the European Ceramic Society, 34[12] 3069-83 (2014).

35 D. Zhu, S. R. Choi, J. I. Eldridge, K. N. Lee, and R. A. Miller, "Surface cracking and interface reaction associated delamination failure of thermal and environmental barrier coatings," (2003).

36 D. Zhu, D. S. Fox, L. J. Ghosn, and B. Harder, "Creep Behavior of Hafnia and Ytterbium Silicate Environmental Barrier Coating Systems on SiC/SiC Ceramic Matrix Composites," (2011).

37 D. Zhu, K. N. Lee, and R. A. Miller, "Thermal gradient cyclic behavior of a thermal/environmental barrier coating system on $\mathrm{SiC} / \mathrm{SiC}$ ceramic matrix composites," pp. 171-78 in ASME Turbo Expo 2002: Power for Land, Sea, and Air. 
38 D. Zhu and R. A. Miller, "Sintering and creep behavior of plasma-sprayed zirconia- and hafnia-based thermal barrier coatings," Surface and Coatings Technology, 108-109[0] 11420 (1998).

39 J. Nicholls, M. Deakin, and D. Rickerby, "A comparison between the erosion behaviour of thermal spray and electron beam physical vapour deposition thermal barrier coatings," Wear, 233 352-61 (1999).

40 X. Chen, M. Y. He, I. Spitsberg, N. A. Fleck, J. W. Hutchinson, and A. G. Evans, "Mechanisms governing the high temperature erosion of thermal barrier coatings," Wear, 256[7] 735-46 (2004).

41 R. Wellman and J. Nicholls, "Erosion, corrosion and erosion-corrosion of EB PVD thermal barrier coatings" Tribology International, 41[7] 657-62 (2008).

42 N. Fleck and T. Zisis, "The erosion of EB-PVD thermal barrier coatings: The competition between mechanisms," Wear, 268[11] 1214-24 (2010).

43 X. Chen, R. Wang, N. Yao, A. Evans, J. Hutchinson, and R. Bruce, "Foreign object damage in a thermal barrier system: mechanisms and simulations," Materials Science and Engineering: A, 352[1] 221-31 (2003).

44 Hengbei Zhao, Bradley T. Richards, Haydn N.G. Wadley, "Molten Silicate Reactions with Ytterbium Silicate Coatings", Submitted (2015).

45 S. Krämer, J. Yang, C. G. Levi, and C. A. Johnson, "Thermochemical Interaction of Thermal Barrier Coatings with Molten $\mathrm{CaO}-\mathrm{MgO}-\mathrm{A} 12 \mathrm{O} 3-\mathrm{SiO} 2$ (CMAS) Deposits," Journal of the American Ceramic Society, 89[10] 3167-75 (2006).

46 S. Krämer, J. Yang, and C. G. Levi, "Infiltration-Inhibiting Reaction of Gadolinium Zirconate Thermal Barrier Coatings with CMAS Melts," Journal of the American Ceramic Society, 91[2] 576-83 (2008).

47 N. L. Ahlborg and D. Zhu, "Calcium-magnesium aluminosilicate (CMAS) reactions and degradation mechanisms of advanced environmental barrier coatings," Surface and Coatings Technology, 237 79-87 (2013).

48 K. M. Grant, S. Krämer, J. Löfvander, and C. G. Levi, "CMAS degradation of environmental barrier coatings," Surface and Coatings Technology, 202[4] 653-57 (2007).

49 D. Zhu, K. N. Lee, and R. A. Miller, "Thermal Conductivity and Thermal Gradient Cyclic Behavior of Refractory Silicate Coatings on SiC/SiC Ceramic Matrix Composites," pp. 44352 in 25th Annual Conference on Composites, Advanced Ceramics, Materials, and Structures: B: Ceramic Engineering and Science Proceedings, Volume 22, Issue 4.

50 D. Zhu, K. N. Lee, and R. A. Miller, "Cyclic Failure Mechanisms of Thermal and Environmental Barrier Coating Systems Under Thermal Gradient Test Conditions," (2002).

51 D. Zhu and R. A. Miller, "Determination of creep behavior of thermal barrier coatings under laser imposed high thermal and stress gradient conditions," Journal of materials research, 14[1] 146-61 (1999).

52 S. M. Meier, Gupta, DK, "Evolution of thermal barrier coatings in gas turbine engine applications," Trans. ASME, J. Eng. Gas Turbines Power, 116 250-57 (1994).

53 N. S. Jacobson, D. S. Fox, J. L. Smialek, C. Deliacorte, and K. N. Lee, "Performance of ceramics in severe environments." in. Edited by GRC. NASA Glenn Research Center, Cleveland, OH, USA, 2005.

54 B. T. Richards, H. Zhao, and H. N. G. Wadley, "Air Plasma Spray Deposition of Ytterbium Silicates," Journal of Materials Science, 50, p. 7939-7957 (2015). 
55 R. A. Golden and E. J. Opila, "A Method for Assessing the Stability of Oxides in HighTemperature High-Velocity Water Vapor," Journal of the American Ceramic Society, Submitted Article (2015).

56 C. W. Bale, P. Chartrand, S. A. Degterov, G. Eriksson, K. Hack, R. Ben Mahfoud, J. Melançon, A. D. Pelton, and S. Petersen, "FactSage thermochemical software and databases," Calphad, 26[2] 189-228 (2002).

57 R. W. Jackson and M. R. Begley, "Critical cooling rates to avoid transient-driven cracking in thermal barrier coating (TBC) systems," International Journal of Solids and Structures, 51[6] 1364-74 (2014).

58 B. T. Richards, L. J. Ghosn, D. Zhu, and H. Wadley, "Mechanical Properties of Air Plasma Sprayed Environmental Barrier Coating (EBC) Systems: Preliminary Assessments," Proceedings of the 39th International Conference and Exposition on Advanced Ceramics and Composites (2015).

59 B. T. Richards, L. J. Ghosn, D. Zhu, and H. Wadley, "Mechanical Properties of Air Plasma Sprayed Environmental Barrier Coating (EBC) Systems: Preliminary Assessments," Proceedings of the 39th International Conference and Exposition on Advanced Ceramics and Composites (2015).

60 D. Taylor, "The thermal expansion behaviour of the framework silicates," Mineralogical Magazine, 38[297] 593-604 (1972).

61 D. Lakshtanov, S. Sinogeikin, and J. Bass, "High-temperature phase transitions and elasticity of silica polymorphs," Phys Chem Minerals, 34[1] 11-22 (2007).

62 T.-I. Mah and K. S. Mazdiyasni, "Mechanical Properties of Mullite," Journal of the American Ceramic Society, 66 699-703 (1983).

63 D. R. Peacor, "High-temperature single-crystal study of the cristobalite inversion," $Z$ Kristallogr, 138 274-98 (1973).

64 Z. Sun, Y. Zhou, J. Wang, and M. Li, " $\gamma-Y 2 S i 2 O 7$, a Machinable Silicate Ceramic: Mechanical Properties and Machinability," Journal of the American Ceramic Society, 90[8] 2535-41 (2007).

65 R. Hull, "Properties of crystalline silicon." IET, (1999).

66 H. Gercek, "Poisson's ratio values for rocks," International Journal of Rock Mechanics and Mining Sciences, 44[1] 1-13 (2007).

67 E. Bourova and P. Richet, "Quartz and Cristobalite: high-temperature cell parameters and volumes of fusion," Geophysical Research Letters, 25[13] 2333-36 (1998).

68 A. Ballato, "Poisson's ratios of auxetic and other technological materials," Ultrasonics, Ferroelectrics and Frequency Control, IEEE Transactions on, 57[1] 7-15 (2010).

69 N. Wiberg, "Holleman-Wiberg's inorganic chemistry," Academic Press, New York (2001).

70 J. B. Bates, "Raman Spectra of $\alpha$ and $\beta$ Cristobalite," The Journal of Chemical Physics, 57[9] 4042-47 (1972).

71 F. L. Galeener, "Raman and ESR studies of the thermal history of amorphous SiO2," Journal of Non-Crystalline Solids, 71[1-3] 373-86 (1985).

72 I. P. Swainson, M. T. Dove, and D. C. Palmer, "Infrared and Raman spectroscopy studies of the $\alpha-\beta$ phase transition in cristobalite," Phys Chem Minerals, 30[6] 353-65 (2003).

73 M. J. Guinel and M. G. Norton, "Oxidation of silicon carbide and the formation of silica polymorphs," Journal of materials research, 21[10] 2550-63 (2006). 
74 P. Patnaik, "Handbook of Inorganic Chemistry." in. ISBN 0-07-049439-8), the McGraw-Hill Companies, 344, 2002.

75 I. A. Bondar, "Rare-earth silicates," Ceramics International, 8 83-89 (1982).

76 D. L. Poerschke, J. S. Van Sluytman, K. B. Wong, and C. G. Levi, "Thermochemical compatibility of ytterbia-(hafnia/silica) multilayers for environmental barrier coatings," Acta Materialia, 61[18] 6743-55 (2013).

77 J. H. Hubbell and S. M. Seltzer, "Tables of X-ray mass attenuation coefficients and mass energy-absorption coefficients $1 \mathrm{keV}$ to $20 \mathrm{MeV}$ for elements $\mathrm{Z}=1$ to 92 and 48 additional substances of dosimetric interest." in. National Inst. of Standards and Technology-PL, Gaithersburg, MD (United States). Ionizing Radiation Div., 1995.

$78 \mathrm{~S}$. Ueno, T. Ohji, and H.-T. Lin, "Recession behavior of Yb2Si2O7 phase under high speed steam jet at high temperatures," Corrosion Science, 50[1] 178-82 (2008).

79 B. E. Deal and A. S. Grove, "General relationship for the thermal oxidation of silicon", J. Appl. Phys, 36 [12], p3770-78 (1965)

80 O. Fabrichnaya, H. Jürgen Seifert, R. Weiland, T. Ludwig, F. Aldinger, and A. Navrotsky, "Phase equilibria and thermodynamics in the $\mathrm{Y} 2 \mathrm{O} 3-\mathrm{Al} 2 \mathrm{O} 3-\mathrm{SiO} 2$ system," Zeitschrift für Metallkunde, 92[9] 1083-97 (2001).

81 W. D. Kingery, H. K. Bowen, and D. R. Uhlmann, "Introduction to Ceramics," p. 240, 2 ed. Wiley: New York, (1976).

82 T. A. Cruse, B. Johnsen, and A. Nagy, "Mechanical properties testing and results for thermal barrier coatings," J Therm Spray Tech, 6[1] 57-66 (1997).

83 J. T. Demasi and M. Ortiz, "Thermal barrier coating life prediction model development, phase $1, "$ (1989).

84 S.-H. Leigh, C.-K. Lin, and C. C. Berndt, "Elastic Response of Thermal Spray Deposits under Indentation Tests," Journal of the American Ceramic Society, 80[8] 2093-99 (1997).

85 C. J. Li and A. Ohmori, "Relationships between the microstructure and properties of thermally sprayed deposits," J Therm Spray Tech, 11[3] 365-74 (2002).

86 S. M. Meier, D. M. Nissley, K. D. Sheffler, and T. A. Cruse, "Thermal barrier coating life prediction model development," Journal of Engineering for gas turbines and power, 114[2] 258-63 (1992).

87 M.R. Begley and H.N.G. Wadley, "Delamination of ceramic coatings with embedded metal layers", J. Am. Ceram. Society, 94, S96-S103, (2011).

88 J. J. Vlassak, "Channel cracking in thin films on substrates of finite thickness," International Journal of Fracture, 119[4] 299-323 (2003).

89 J. L. Beuth, Jr., Cracking of thin bonded films in residual tension. International Journal of Solids and Structures 29, 1657-1675, (1991).

90 D. Tromans and J. A. Meech, "Fracture toughness and surface energies of covalent minerals: theoretical estimates," Minerals Engineering, 17[1] 1-15 (2004). 


\section{Figures}

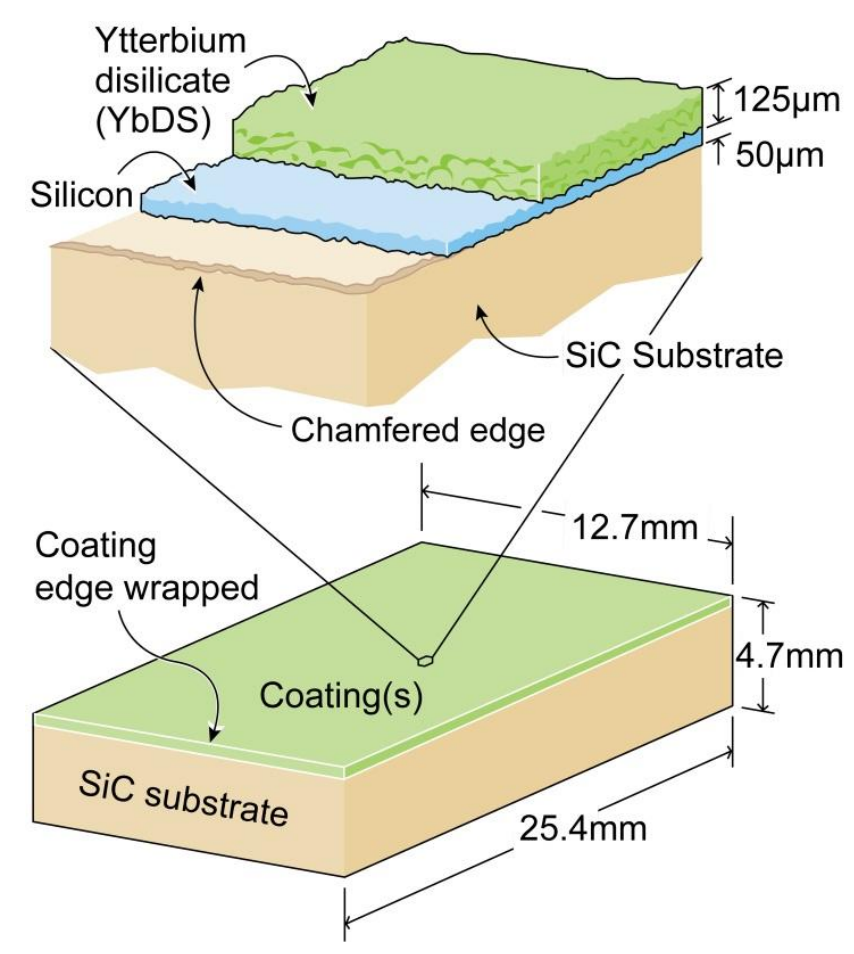

Figure 1: Schematic illustration of a bi-layer $\mathrm{Yb}_{2} \mathrm{Si}_{2} \mathrm{O}_{7} / \mathrm{Si}(\mathrm{YbDS} / \mathrm{Si}$ ) coated $\alpha-\mathrm{SiC}$ substrate. 


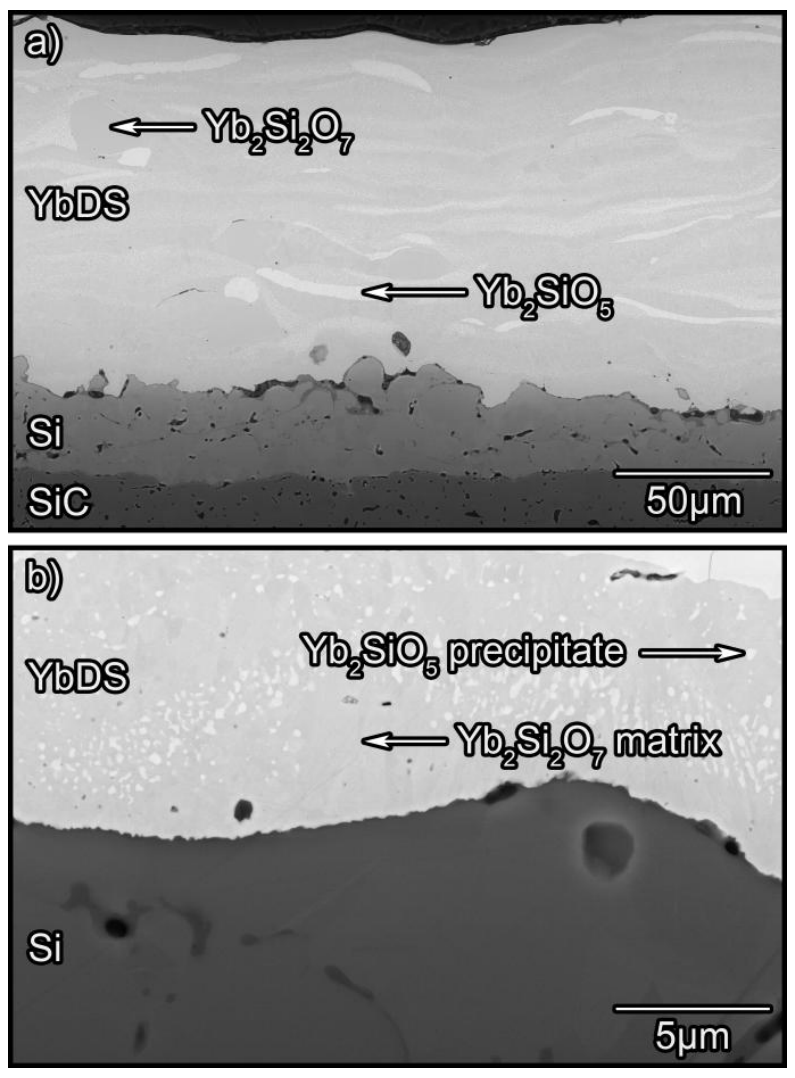

Figure 2: BSE images of a stabilization annealed YbDS/Si bi-layer coating deposited onto $\alpha-\mathrm{SiC}$. (a) Low magnification image showing two phases in the YbDS topcoat. (b) Higher magnification view of the $\mathrm{YbDS}-\mathrm{Si}$ interface showing interface structure and small $\mathrm{Yb}_{2} \mathrm{SiO}_{5}(\mathrm{YbMS})$ precipitates (of lighter contrast) in the YbDS topcoat. 


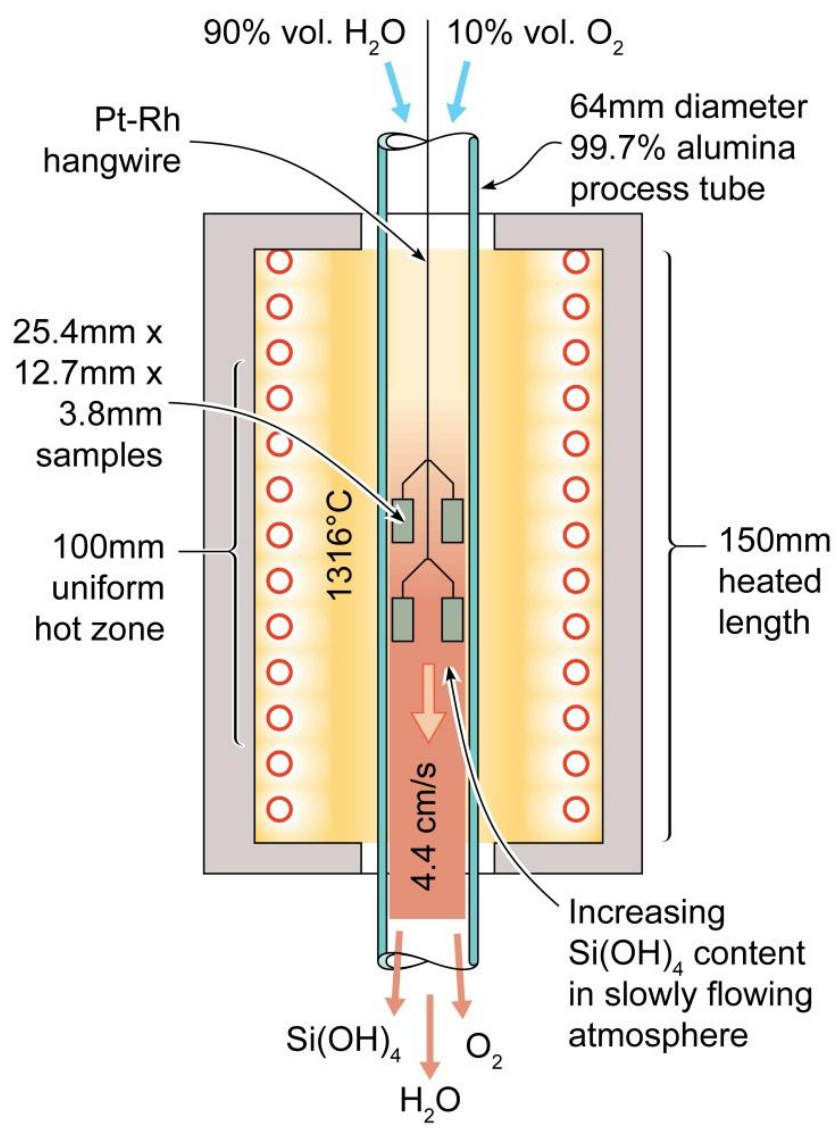

Figure 3: Schematic illustration of the testing geometry and environment local to the samples during the hot part cycle of the steam-cycle. The furnace was raised after $1 \mathrm{hr}$ reducing the sample temperature from $1316{ }^{\circ}$ to $110{ }^{\circ} \mathrm{C}$. 

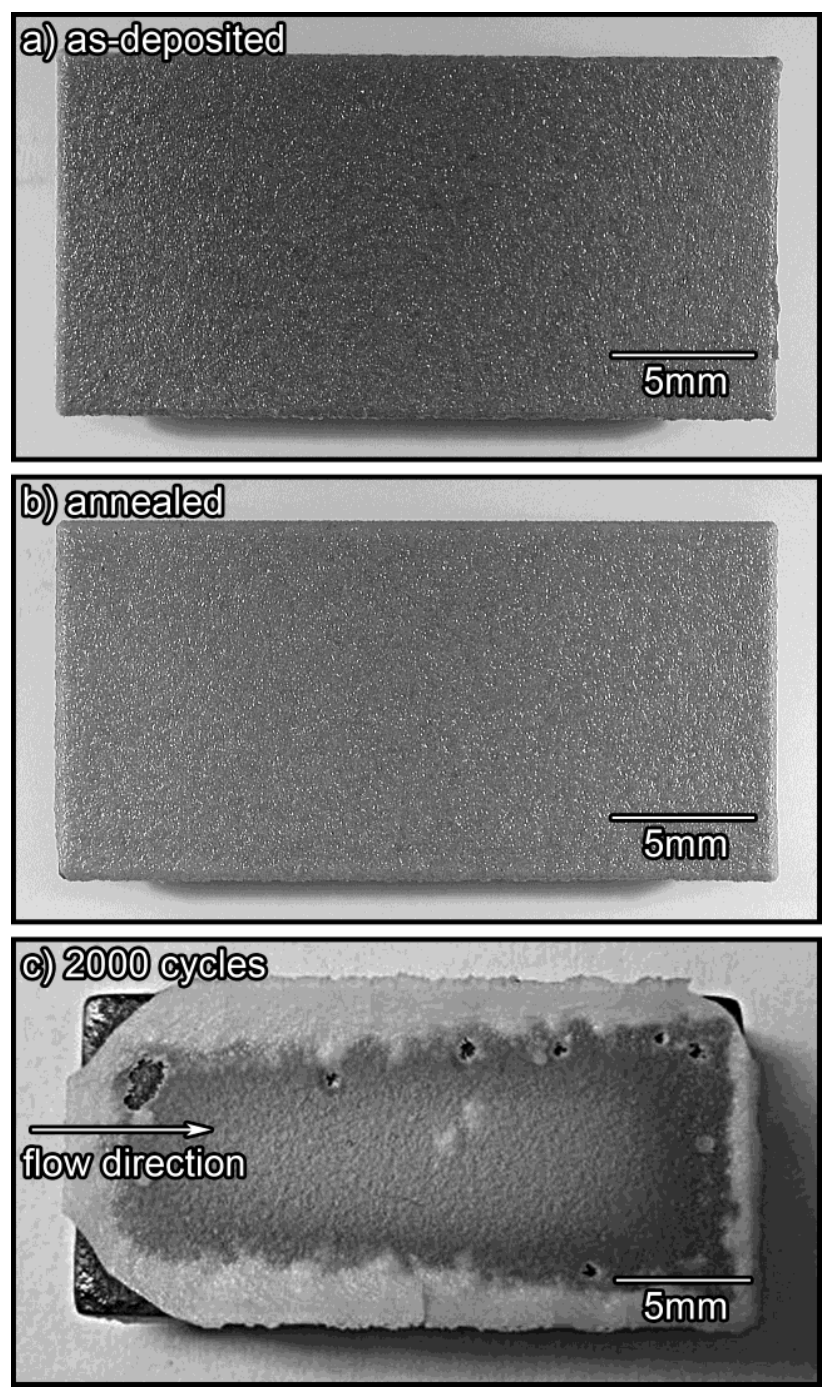

Figure 4: Optical images of $\mathrm{YbDS} / \mathrm{Si}$ coated SiC substrates. (a) As-deposited, (b) annealed, and (c) after 2000 steam cycles at $1316^{\circ} \mathrm{C}$ with the gas flow direction indicated. The lighter contrast region around the edge of the sample in (c) correspond to regions of the coating that had partially delaminated from the substrate. 

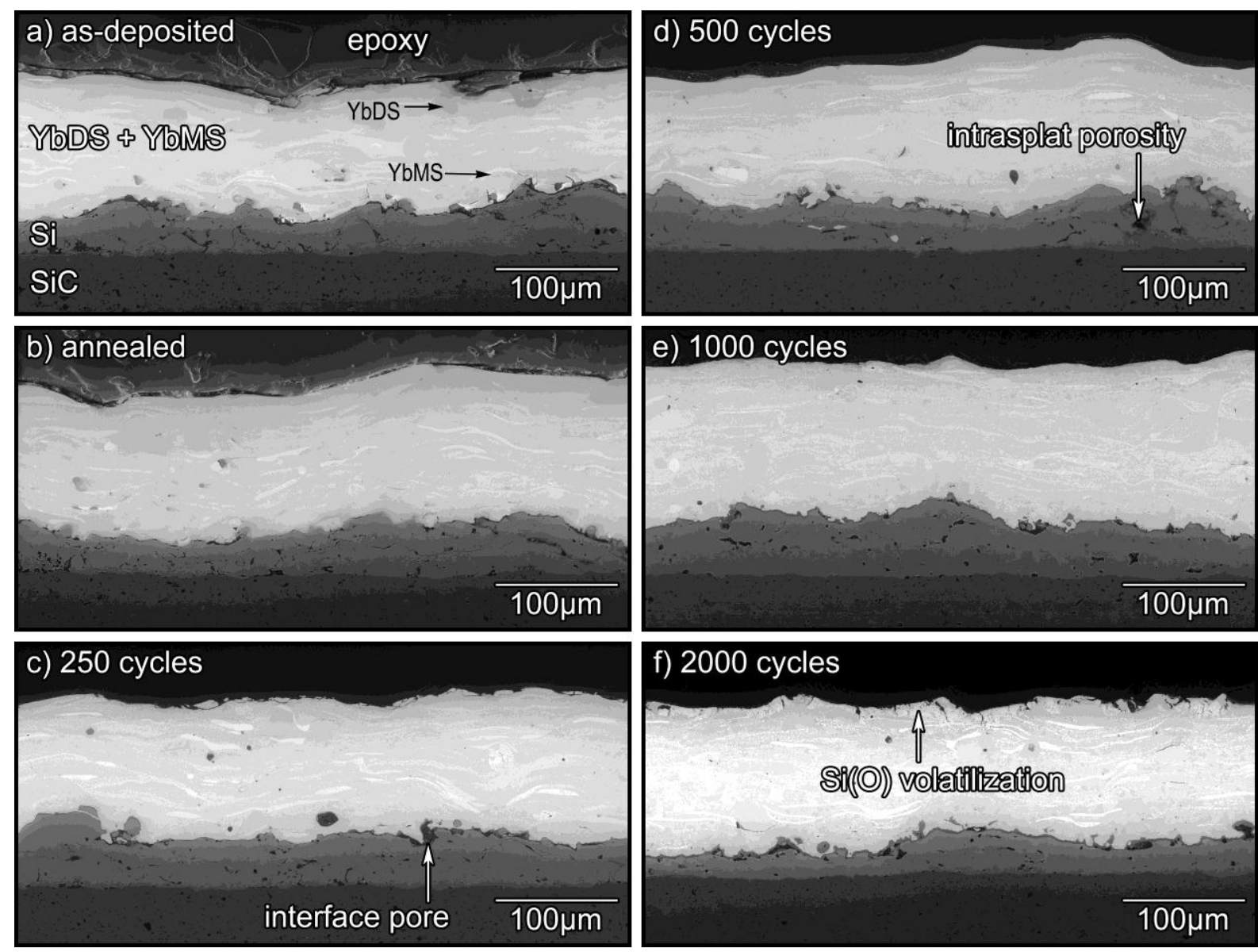

Figure 5: BSE mode SEM micrographs of $\mathrm{YbDS} / \mathrm{Si}$ coated system before and after steam cycling. (a) As-deposited, (b) annealed, (c) after 250 steam cycles, (d) 500 cycles, (e) 1000 cycles, and (f) 2000 cycles. 

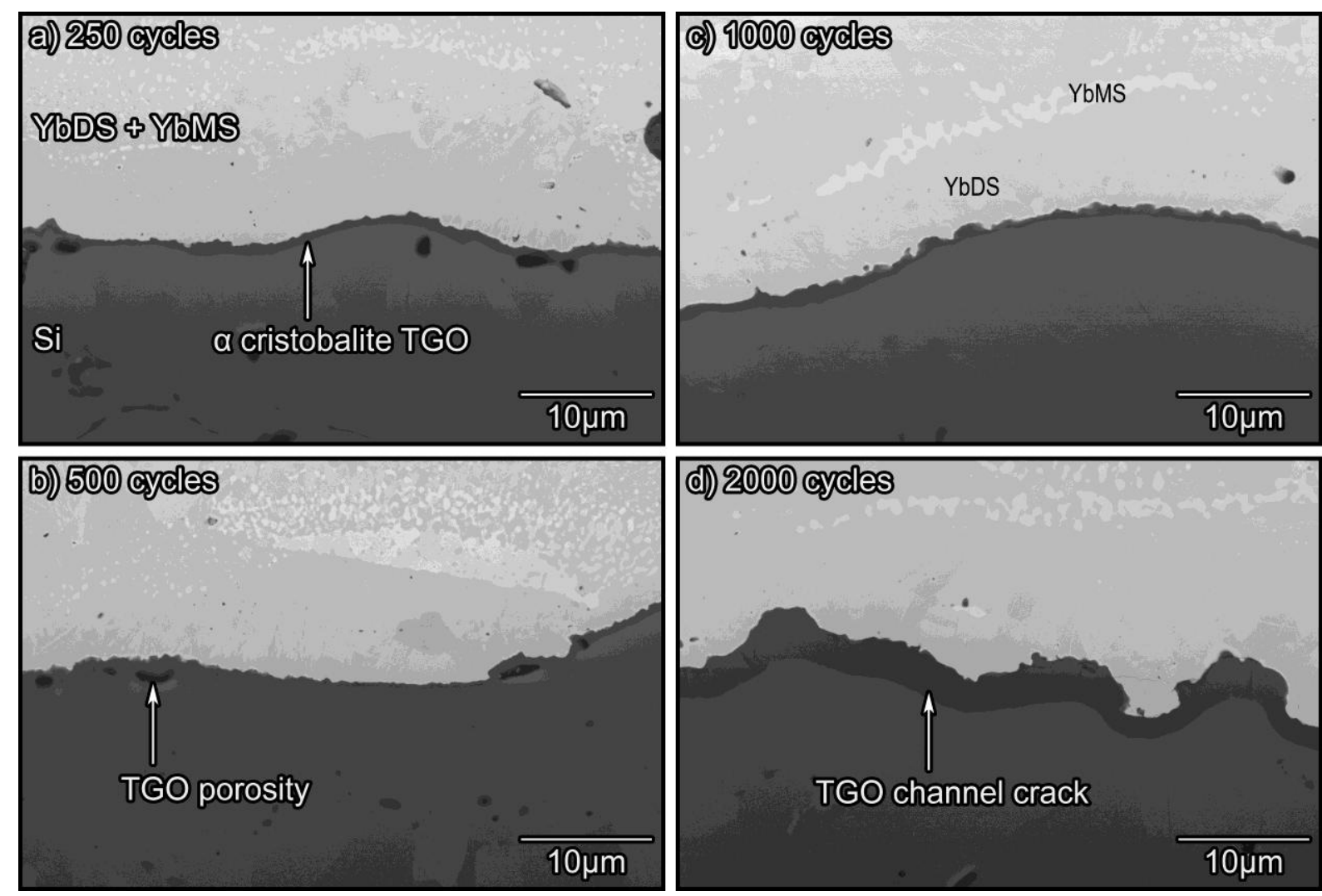

Figure 6: BSE micrographs of the YbDS - Si interface after steam cycling showing the development of a thermally grown oxide (TGO). (a) After 250, (b) 500, (c) 1000, and (d) 2000 cycles at $1316^{\circ} \mathrm{C}$ with $90 \% \mathrm{H}_{2} \mathrm{O} / 10 \% \mathrm{O}_{2}$ flowing at $44 \mathrm{~mm} / \mathrm{s}$. 


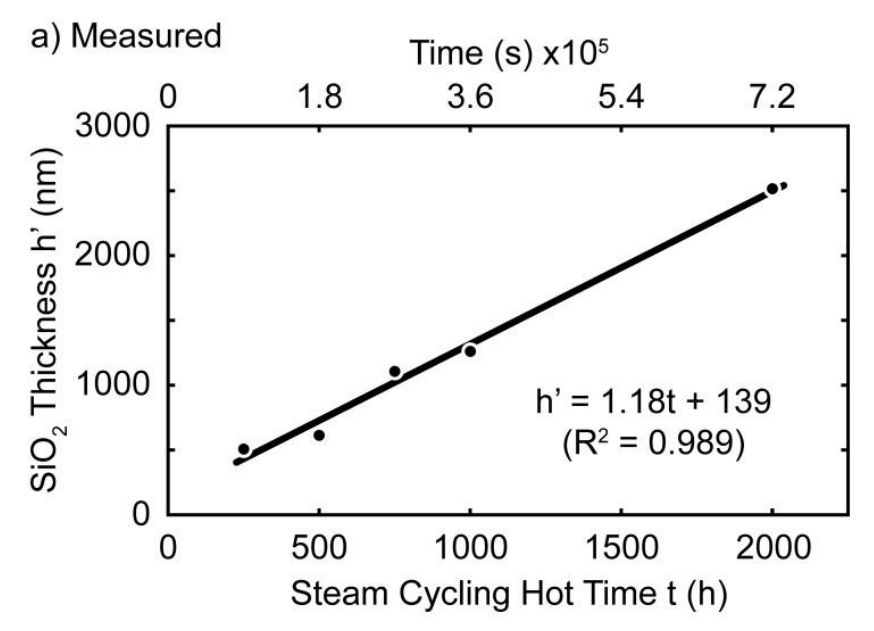

b) Thickness Corrected Time (s) $\times 10^{5}$

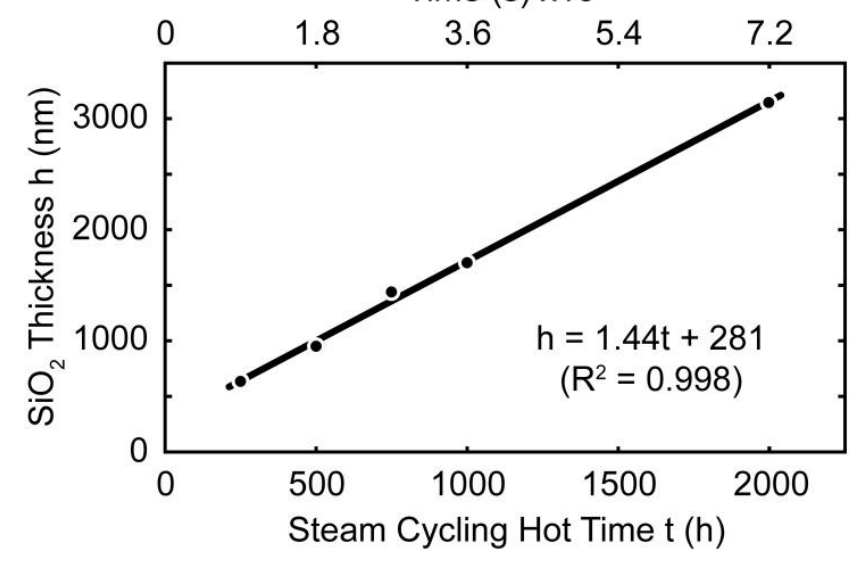

Figure 7: Plots of $\mathrm{SiO}_{2} \mathrm{TGO}$ thickness as a function of accumulated exposure time at $1316^{\circ} \mathrm{C}$ for a bi-layer EBC. (a) Average thicknesses measured from multiple samples with varying YbDS layer thickness. (b) Average thicknesses normalized for thermally grown silica beneath a $100 \mu \mathrm{m}$ thick YbDS layer. 

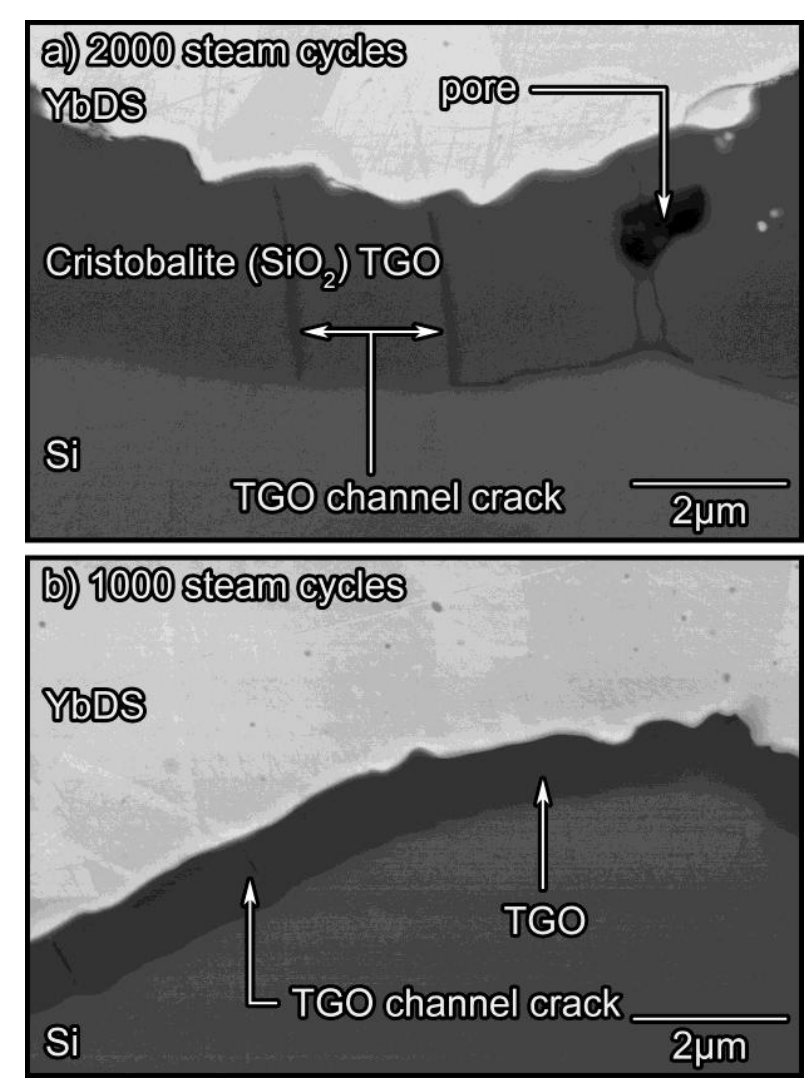

Figure 8: BSE micrograph of the thermally grown cristobalite $\left(\mathrm{SiO}_{2}\right)$ oxide at the $\mathrm{YbDS}-\mathrm{Si}$ interface during steam cycling. (a) TGO at the YbDS - Si interface after 2000 steam cycles, (b) after 1000 steam cycles. 


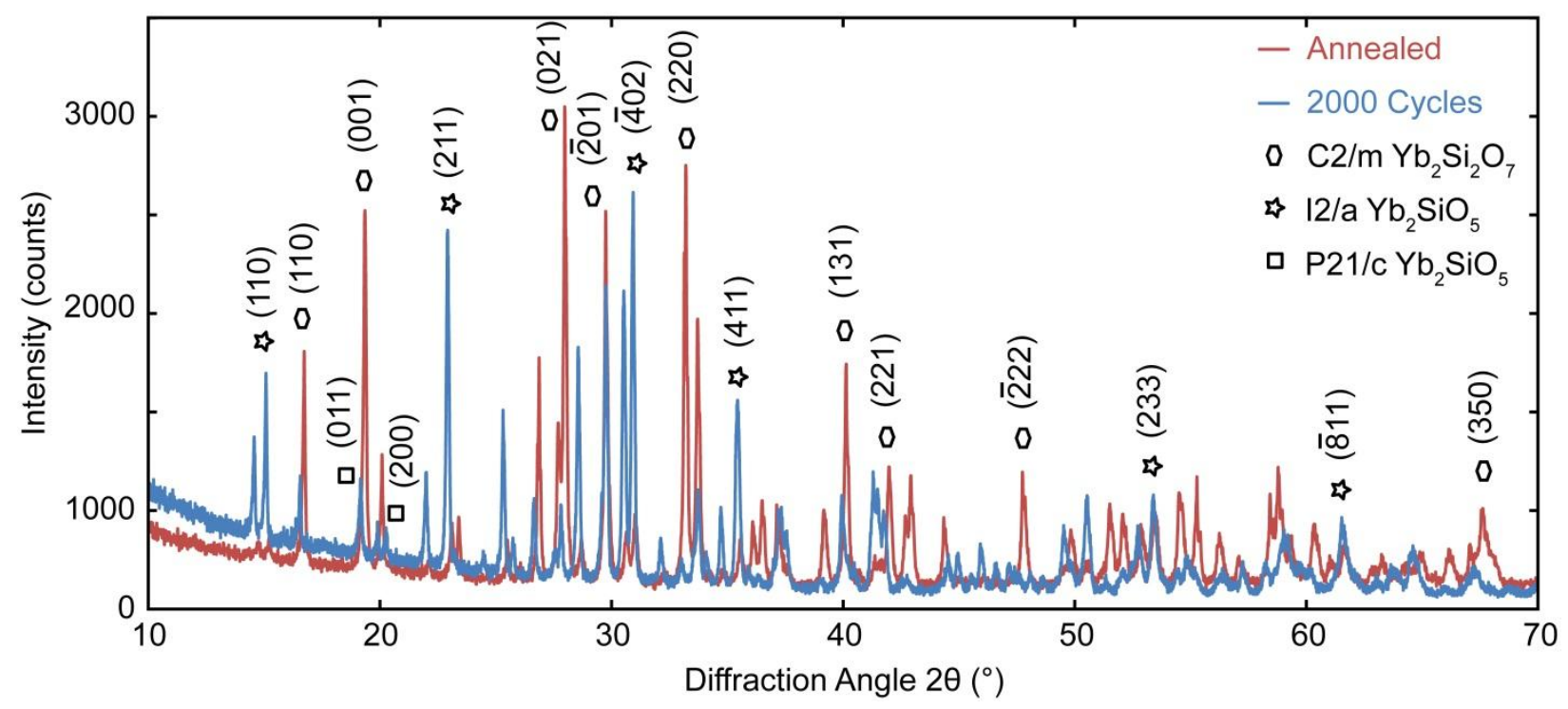

Figure 9: X-ray diffraction patterns of the annealed and 2000 steam-cycle sample surfaces. All peaks of the patterns have been indexed using equilibrium $\mathrm{YbDS}(\mathrm{C} 2 / \mathrm{m})$ and equilibrium $\mathrm{I}$ /a and metastable P21/c YbMS peaks. The slightly elevated background of the 2000 cycle pattern results from a very thin layer of epoxy on the surface that was used to prevent coating spallation during handling. 

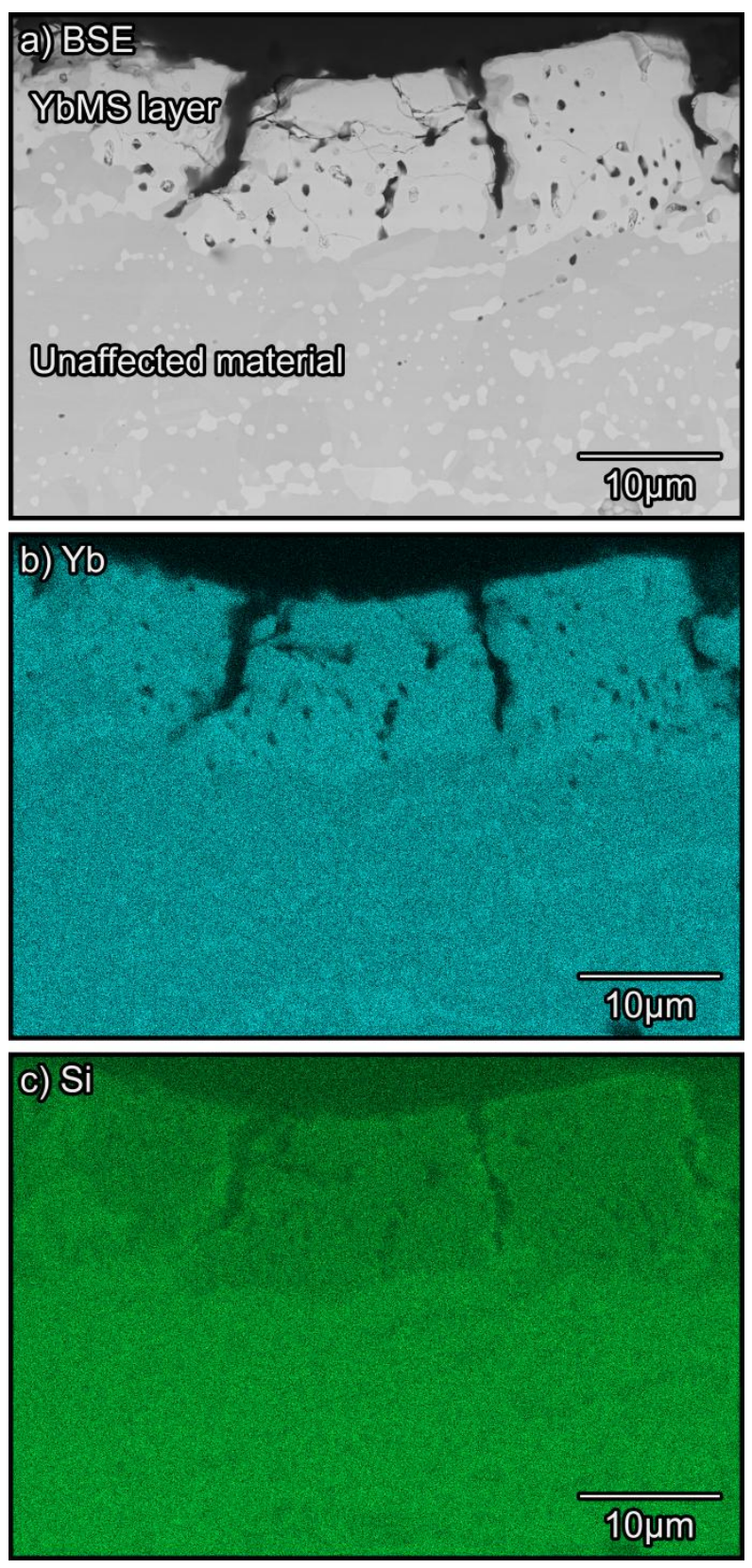

Figure 10: (a) BSE micrograph of a surface volatilized region of the topcoat. (b) A dot map for $\mathrm{Yb}$, and (c) a dot map for Si of the same region shown in (a) from EDS analysis. 

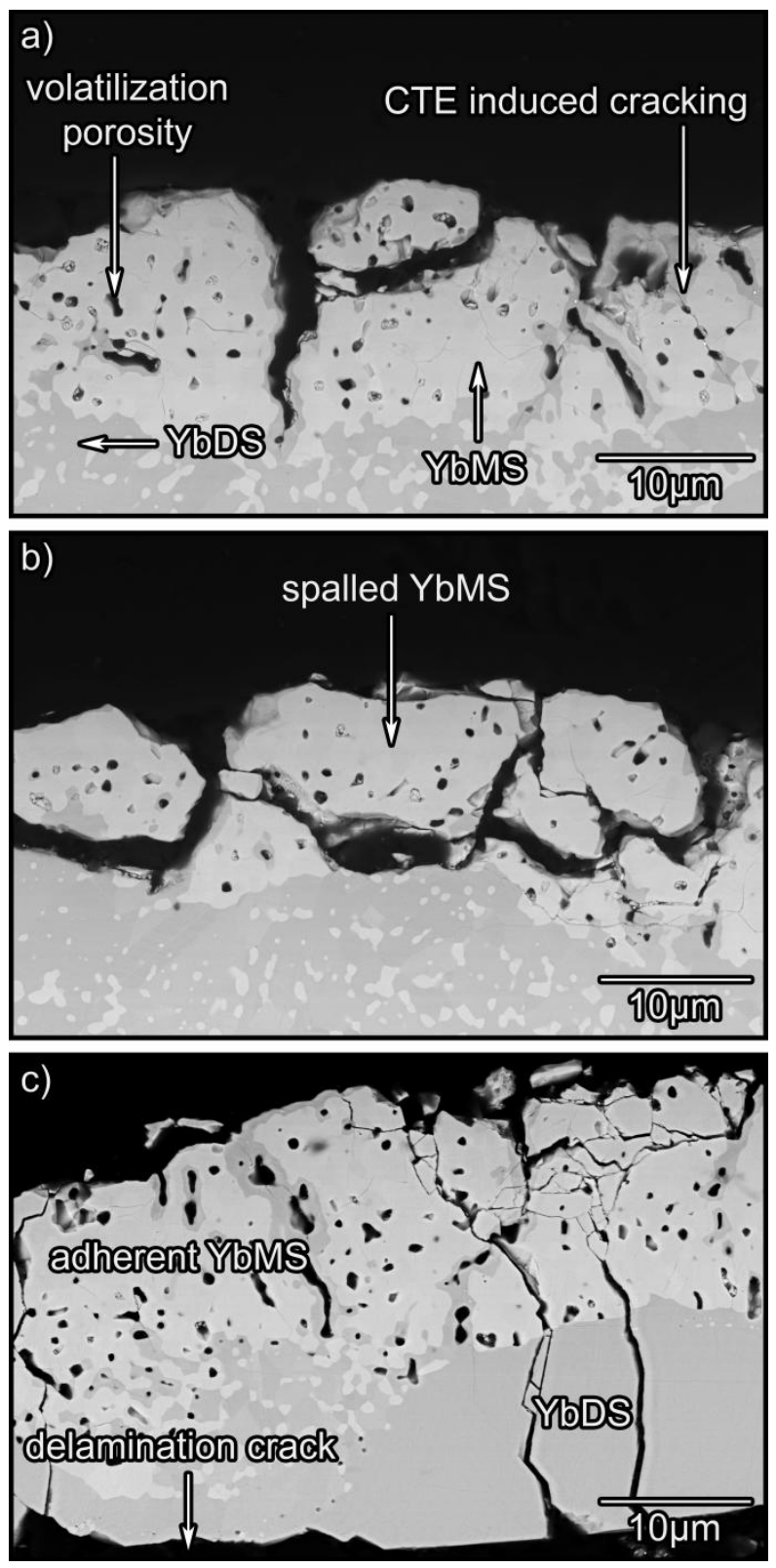

Figure 11: BSE cross-section micrographs showing $\mathrm{SiO}_{2}$ volatilization from the YbDS surface after 2000 steam cycles at $1316^{\circ} \mathrm{C}$. (a) Adherent area of YbMS with porosity and microcracking. (b) Spalled region of surface volatilized layer. (c) Delaminated region of coating containing steam-reduced YbMS and region of less affected YbDS. 

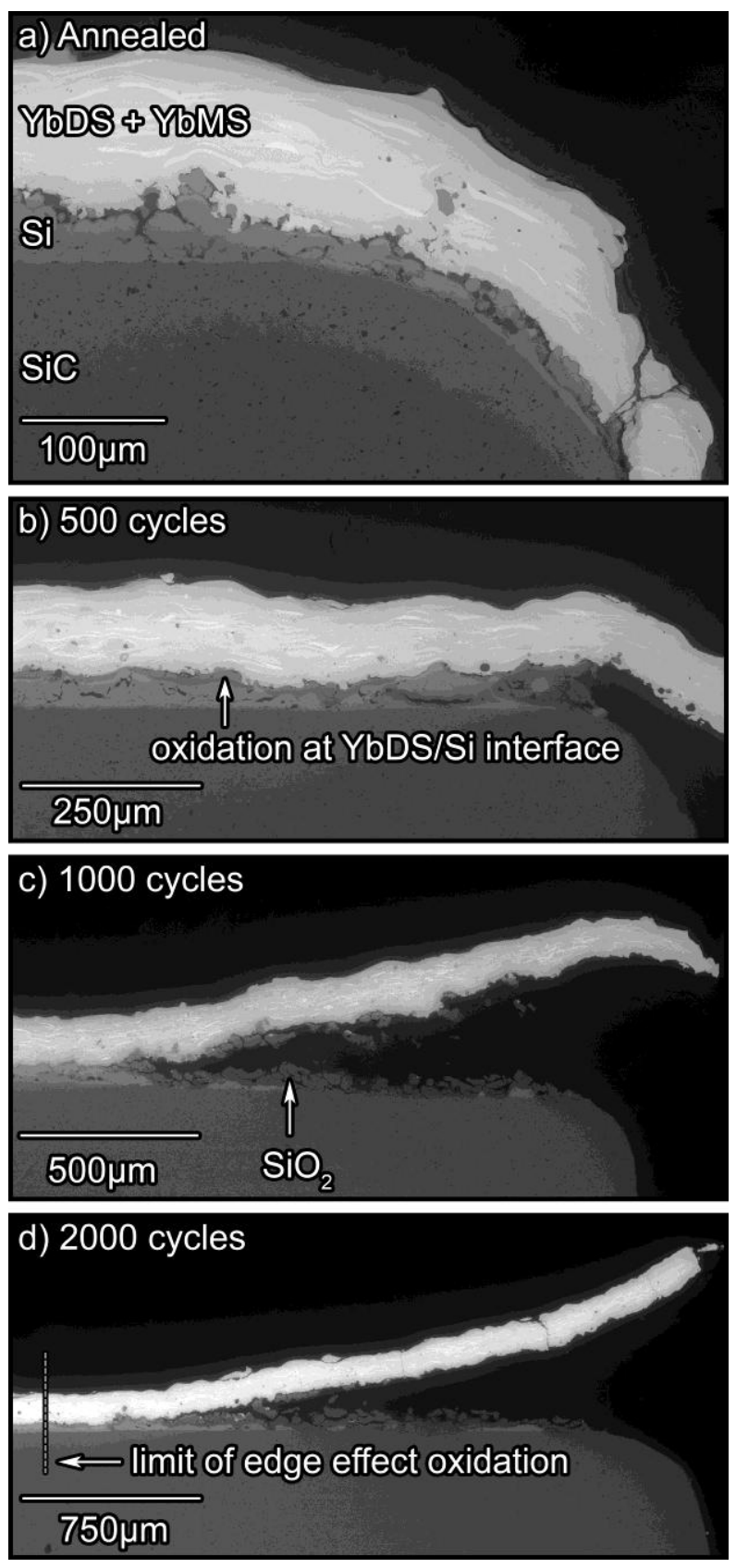

Figure 12: BSE micrographs of coating edges showing edge attack during steam cycling of the bi-layer EBCs. (a) Annealed coating with an over-sprayed edge, (b) edge TGO growth after 500 steam cycles, (c) significant edge lifting after 1000 steam cycles, and (d) example of extension of the edge delamination after 2000 steam cycles. 

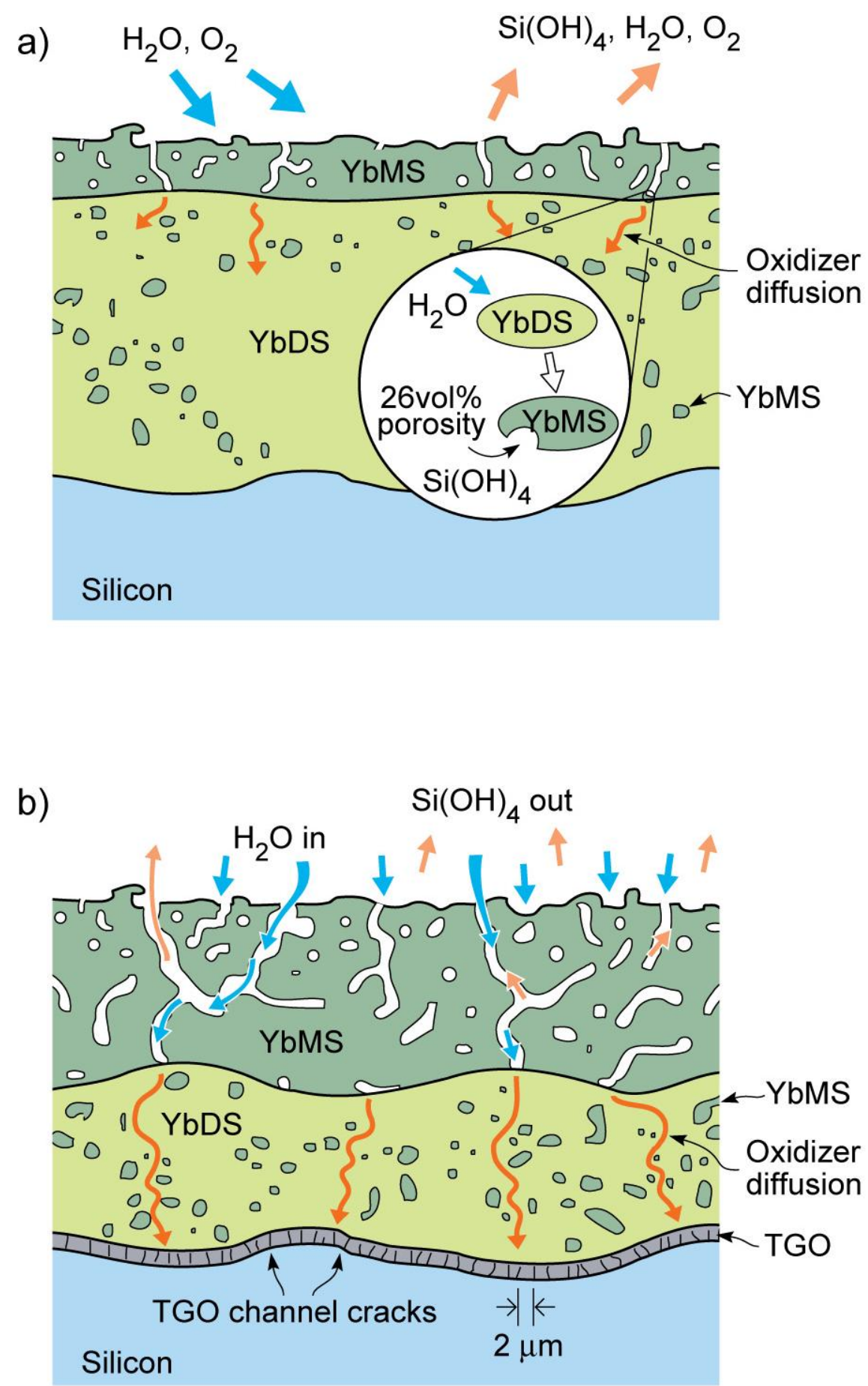

Figure 13: Schematic illustration of the silica volatilization mechanism that results in a porous surface layer of YbMS on the exposed YbDS surface and a TGO layer on the silicon bond coat after steam cycling. (a) Initial stage of volatilization and (b) late in the exposure process. The growth of a microcracked TGO when the oxidizing species reaches the bond coat is also shown. 

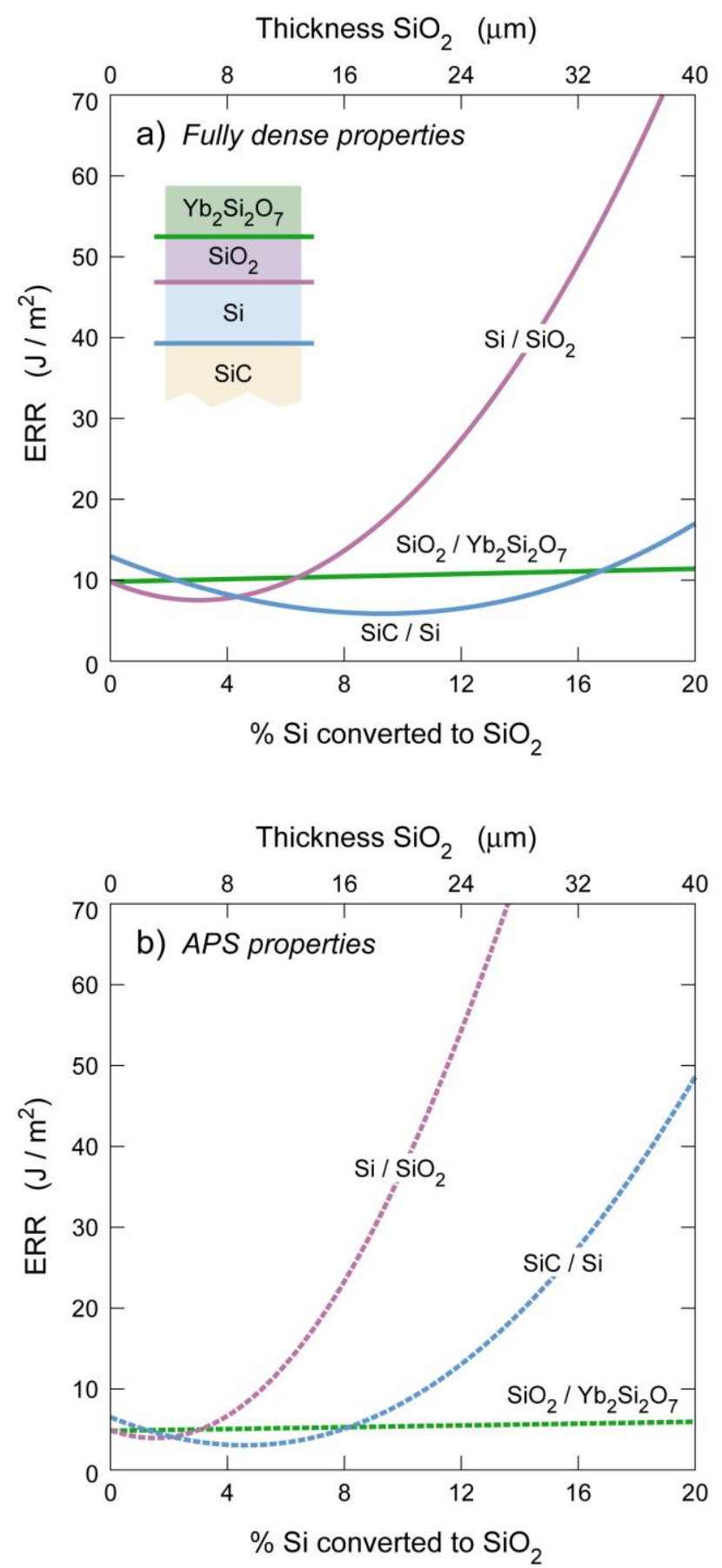

Figure 14: Predicted strain energy release rates during delamination of the interfaces in the YbDS - Si EBC system after cooling from $1316^{\circ} \mathrm{C}$ to $20^{\circ} \mathrm{C}$. The calculations in (a) used the elastic properties of solid YbDS and silicon layers while (b) used estimated values for the mechanical properties of YbDS with APS with the APS structure. All mechanical properties used during the calculations are listed in Table 2. 
a) Early in steam cycling

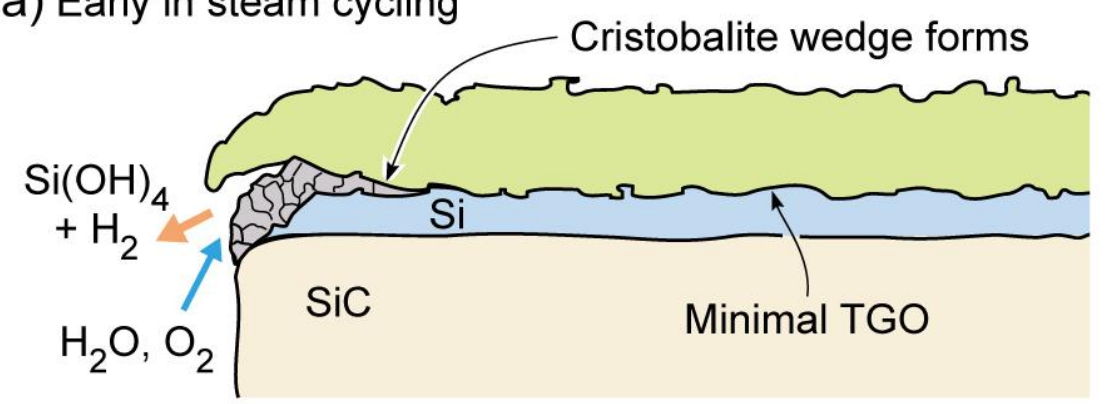

b) Late in steam cycling

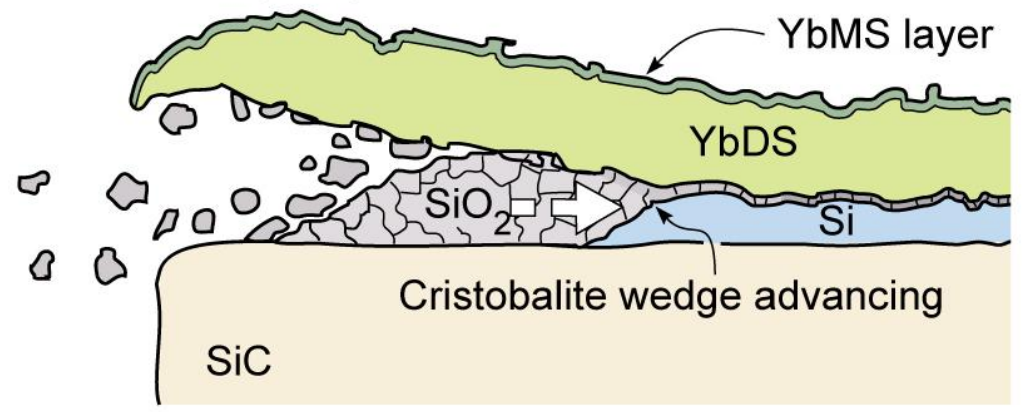

Figure 15: Schematic illustration of the TGO wedging mechanism that caused edge lifting during steam cycling of a $\mathrm{YbDS} / \mathrm{Si} \mathrm{EBC}$ deposited on $\mathrm{SiC}$. (a) Shows the early stage where a $\mathrm{SiO}_{2} \mathrm{TGO}$ forms at the edge of the sample and begins to vertically displace (wedges) the EBC above. (b) Shows a later stage of the process where the TGO has been eroded by steam erosion creating a region of topcoat that is unattached to the bond coat. The loss of $\mathrm{SiO}_{2}$ from the outer surface of the YbDS layer, results in a high CTE YbMS that causes outward bending of the unattached YbDS topcoat. 
a) Early in steam cycling

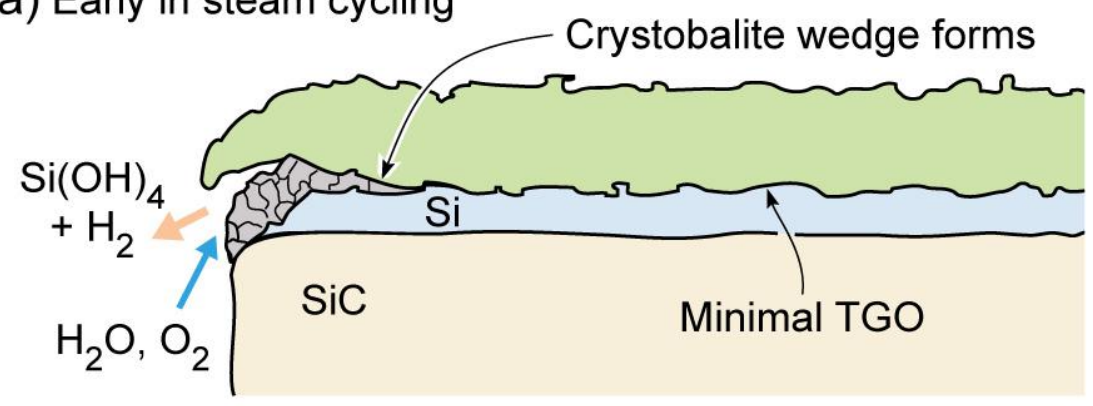

b) Late in steam cycling

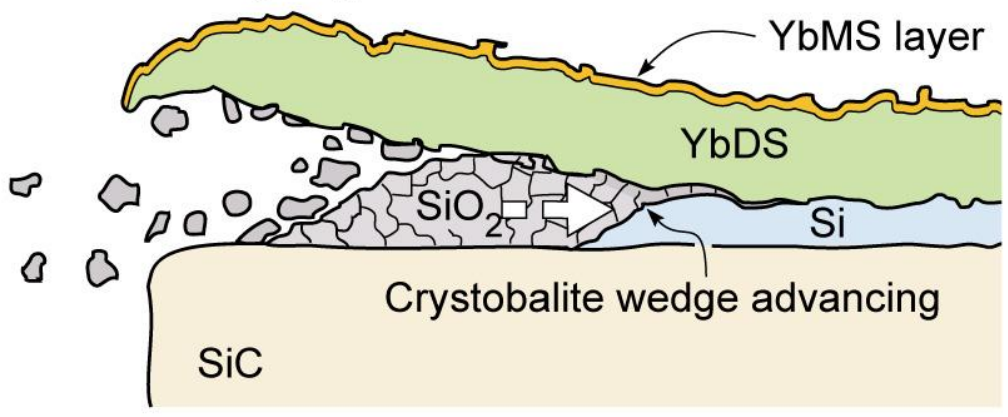

